\title{
Hacia una nueva definición del Neolítico Medio en el sur de la península ibérica: Grañena Baja, Jaén*
}

\author{
Towards a new definition of the Middle Neolithic in the southern Iberian peninsula: \\ Grañena Baja, Jaén
}

\author{
Elisabet Conlin Hayes ${ }^{\mathrm{a}}$, Rafael M. Martínez Sánchez ${ }^{\mathrm{b}}$ y Antonio Morgado $^{\mathrm{b}}$
}

\section{RESUMEN}

En este trabajo presentamos los resultados de las excavaciones en el yacimiento arqueológico de Grañena Baja (Jaén), correspondientes a la primera fase detectada en el mismo. Destaca la posible existencia de un gran foso segmentado, asociado a una cultura material hasta ahora no caracterizada de forma específica en el sur de la península ibérica. Cerámicas de perfil compuesto y borde reforzado con decoraciones sencillas componen el registro. Láminas de formato medio y grande, talón liso y extraídas por percusión indirecta caracterizan los instrumentos líticos. Las dataciones disponibles sitúan en el tercer cuarto del V milenio cal AC el momento de plena ocupación en dicha fase. Esas características dotan al yacimiento de un valor excepcional para completar el vacío existente entre el Neolítico Antiguo y el Neolítico Reciente en gran parte del mediodía peninsular, donde los contextos asociados a dichas cronologías son escasos. Grañena Baja constituye pues una oportunidad única para la caracterización de un Neolítico Medio hasta ahora escurridizo.

\begin{abstract}
This work presents the results of the first phase detected at the archaeological site of Grañena Baja (Jaén). The possible existence of a large segmented ditch is one of the most outstanding features, associated with a material culture that has not been specifically characterized in the southern Iberia. The ceramic types stand out for their composite profile and reinforced rims, as well as having decorations simply executed. Blades of medium and large format with straight bases and obtained by means of indirect percussion charac-
\end{abstract}

terize the lithic industry. Radiocarbon dates place the site's occupation in the third quarter of the $5^{\text {th }}$ Millennium cal BC. This information makes an important contribution to filling the gap between the Early and the Recent Neolithic in southern Iberia, a region where good evidence for the Middle Neolithic is scarce.

Palabras clave: Neolítico Medio; Andalucía; Alto Guadalquivir; Fosos segmentados; Dataciones radiocarbónicas; Cambio tecnológico; Cerámicas de borde reforzado.

Key words: Middle Neolithic; Upper Guadalquivir; Segmented ditches; Radiocarbon dates; Technological change; Reinforced rim pottery.

\section{INTRODUCCIÓN}

Se ha dedicado escasa atención a las fases avanzadas del Neolítico en gran parte del sur de la península ibérica por una aparente laguna en la documentación arqueológica que se refleja en las series radiocarbónicas. Esta laguna, de explicación discutida y aún no resuelta, coincide con gran parte del $\mathrm{V}$ y la primera mitad del IV milenio cal AC (Balsera et al. 2015: 141; Martín et al. 2017: 459; Molina et al. 2017). Otro factor explicativo es la caracterización del denominado Neolítico Medio como mera fase a caballo entre el Neolítico Antiguo y el Reciente o Final (Navarrete et al. 1991; Pellicer 1995; Carrasco et al. 2011a, 2011b; Molina et al. 2012) a partir de categorías que proyectan realidades distintas para cada investigador.

* La empresa Laura Mercado Gestión del Patrimonio y Servicios Arqueológicos, SLU, realizó la excavación dirigida por Elisabet Conlin con el apoyo técnico de Laura Mercado, Inés Casas, Rosa Gil, Miguel López, Manuel Silva (†), Juan M. Guijo y Elena Vera. Parte del estudio subsecuente y la redacción de este trabajo se financiaron gracias a un contrato Juan de la Cierva (RMMS) del Programa Estatal de Promoción del Talento y su Empleabilidad, Plan Estatal de Investigación Científica y Técnica de Innovación 2013-2016 (MINECO).

a C/ Marqués de la Mina 7, 20 izq. 41002 Sevilla. España. Correo e.: elisabetconlin@hotmail.com https://orcid.org/0000-0002-9991-8385

b Dept. de Prehistoria y Arqueología. Universidad de Granada. Campus de Cartuja s/n. 18071 Granada. España. Correos e.: rmmartinez@ugr.es https://orcid.org/0000-0002-8947-117X; morgado@ugr.es https://orcid.org/0000-0002-8227-2194

Recibido 7-5-2019; aceptado 17-9-2019. 
A lo largo de las tres últimas décadas del siglo XX, la aceptación generalizada de la datación convencional por radiocarbono coincide con la identificación de una fase antigua dentro del Neolítico, definida por la cerámica impresa cardial con mayor presencia en el noreste y levante mediterráneo. Los conjuntos del sur peninsular se consideraron tardíos, por estar dominados por cerámicas de engobe rojo a la almagra, incisas e impresas no cardiales (Gavilán y Vera 2001: 178). Los conjuntos neolíticos meridionales, procedentes de cuevas con cerámicas decoradas, tradicionalmente incluidos en la denominada "Cultura de las Cuevas" (Navarrete et al. 1991) quedaron dentro de una fase media. Esta asociación se extendió a una gran cantidad de yacimientos en cueva de la Alta Andalucía. De este modo se asumía una mayor antigüedad para los conjuntos cardiales de otros yacimientos andaluces (Navarrete 1976).

En esta imagen tripartita del Neolítico en Andalucía, el Neolítico Medio representaba un horizonte de gran expansión y desarrollo, definido por formas cerámicas ya presentes en el Neolítico Antiguo, con decoraciones impresas no cardiales, incisas y a la almagra. El Neolítico Reciente, que ya entonces se preveía inusitadamente largo, se subdividía en un primer momento, también llamado Neolítico Tardío, donde se observaba un "empobrecimiento" de los tipos decorados. Desde este momento surgían grandes formas abiertas que daban paso, ya en un Neolítico Final, a los primeros recipientes de carena baja propios del Cobre Antiguo (Arribas y Molina 1979; Navarrete et al. 1991; Pellicer 1995: 91-101; Pérez et al. 1999: 488). La interpretación del modelo se resumía en grupos de pastores con asentamientos en cueva estacionales, gradualmente sedentarizados por influencia de grupos vecinos del Sureste y valle del Guadalquivir. Sin embargo, el avance de la investigación hará cada vez más evidente la existencia de asentamientos al aire libre con una cultura material afín (Sáez y Martínez 1981; Carrasco et al. 1987).

Durante la década de 1990, el panorama se modificó sustancialmente gracias a excavaciones en poblados y en extensas áreas ocupacionales. En el Alto Guadalquivir, la excavación del poblado de la Alberquilla-Polideportivo de Martos vino a significar la Fase 0 , trazada por F. Nocete (1994: 277, 283), como parte de un pretendido modelo swidden. Durante la misma se produciría la colonización agrícola de las campiñas, hasta entonces sólo ocupadas estacionalmente por poblaciones "trogloditas" muy dependientes del entorno montañoso del piedemonte subbético (Nocete 2001: 67). La extrema antigüedad de las primeras dataciones en dicho yacimiento retrasaría la expansión de las formas carenadas, asumidas como parte tanto del Neolítico Final como de los inicios de la Edad del Cobre (Lizcano et al. 2004: 165). Revisiones posteriores proporcionaron intervalos más recientes (3400-2900 cal AC), a partir de dataciones de depósitos sepulcrales (Cámara et al. 2010: 305; Cámara y Riquelme 2015: 346).

Para este momento ya eran conocidos establecimientos al aire libre en las áreas más orientales de las campiñas del Alto Guadalquivir, en el piedemonte de Sierra Mágina y Sierra de Cazorla (Zafra y Pérez 1993; Zafra 2006: 108; Pérez 2010: 136). Sin embargo, en las denominadas campiñas occidentales del Alto Guadalquivir, la ocupación neolítica resultaba difícil de rastrear, pese a excepciones como Peña de la Grieta, en Porcuna o algunos yacimientos citados en el área de Jaén (Arteaga et al. 1998: 80; Nocete 2001: 67). Aparentemente las comunidades neolíticas de la segunda mitad del VI y V milenio cal AC estaban disociadas de un territorio que se presuponía baldío, paradójicamente ajeno a la explotación agrícola y ganadera que estas primeras comunidades productoras, ya hacía siglos realizaban en los entornos montañosos de las cordilleras Béticas de la Alta Andalucía.

Al parecer la sedentarización definitiva habría de producirse en momentos que, traducidos en términos histórico-culturales, corresponderían a un Neolítico Final-Calcolítico Inicial y que dejarían el tablero preparado para las nuevas formas sociales propias de la Edad del Cobre (Cámara y Riquelme 2015). Los enterramientos individuales y colectivos efectuados en estructuras siliformes, así como el sacrificio e inhumación ritual de animales, a veces acompañados de cuerpos humanos, encarnarían las primeras evidencias de complejización social en un territorio dotado de una alta productividad para los cereales de secano (Lizcano et al. 1992: 50; Nocete 1994: 289).

En este contexto cronocultural los recintos de fosos comienzan a ser una constante en el paisaje arqueológico del sur de la península. Los trazados de dichas construcciones fundamentalmente son continuos, más raramente sinuosos y con frecuencia varios se articulan en estructuras concéntricas. Frente a lo observado en otras regiones en cronologías anteriores, los recintos segmentados constituyen uno de los tipos más escasos (Bernabeu et al. 2017: 343).

\section{UN ENCLAVE DE OCUPACIÓN REITERADA JUNTO AL GUADALBULLÓN}

El yacimiento arqueológico de Grañena Baja fue intervenido entre 2011 y 2016 siguiendo las obras de construcción de la Línea de Alta Velocidad MadridAlcázar de San Juan-Jaén, Tramo Grañena-Jaén. Sus coordenadas geográficas son $37^{\circ} 52^{\prime} 16.15^{\prime} \mathrm{N}$ y $3^{\circ} 46^{\prime} 6.40^{\prime \prime} \mathrm{O}$. El sitio ocupa un espolón amesetado en la margen izquierda del río Guadalbullón sobre el que 


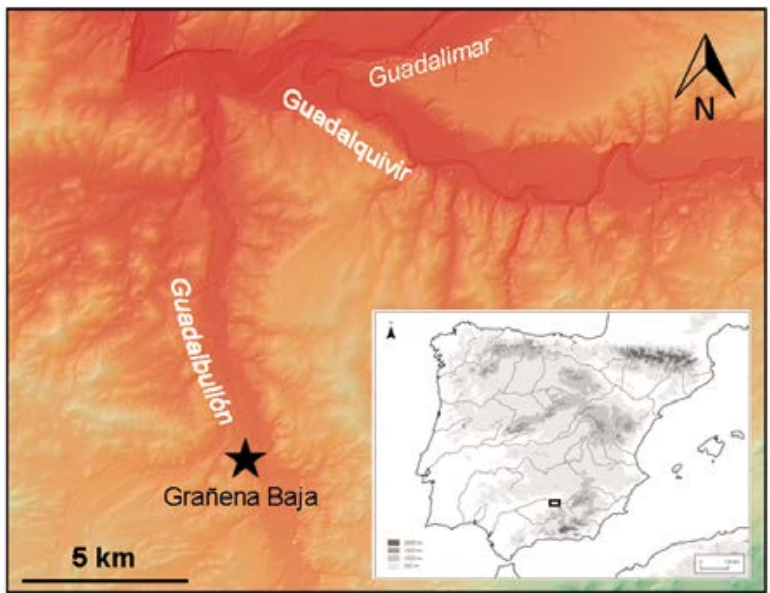

Fig. 1. Situación del yacimiento arqueológico de Grañena Baja (Jaén) en la margen izquierda del río Guadalquivir y en la península ibérica. Modelo orográfico a partir del MDT05, IGN (en color en la versión electrónica).

ocupaciones de distintos periodos históricos se reparten en un espacio de 30 ha de extensión (Fig. 1). De norte a sur diversos trazados de comunicación y ejes viarios, casi paralelos entre sí, desfiguran la topografía original del terreno.

La eliminación mecánica del suelo de cultivo permitió detectar la mayor parte de las estructuras como paso previo a su total excavación manual. Esta se extendió a la totalidad de la superficie afectada, registrando cada una de las unidades estratigráficas. Se tamizó la totalidad del terrígeno procedente de los contextos de mayor interés: la colmatación inicial de las estructuras, niveles orgánicos o contextos con restos humanos. Así se pudo recuperar un interesante conjunto de macrorrestos arqueobotánicos ${ }^{1}$.

Los trabajos documentaron 213 estructuras negativas, en general de planta circular, así como tres grandes estructuras tipo foso. La cultura material junto con las dataciones radiocarbónicas obtenidas permitieron definir cuatro grandes fases de ocupación desde mediados del $\mathrm{V}$ milenio hasta avanzado el III milenio cal AC:

Sobre la Fase I, la más antigua, versa este trabajo, por lo que aquí no entraremos en detalle.

La Fase II está definida por el hallazgo de 80 construcciones negativas, en su mayoría de planta circular. Predominaban las estructuras domésticas amortizadas, siliformes o en forma de cubeta, que se agrupaban en la zona suroeste del área intervenida. Algunas de estas estructuras se habían excavado sobre la colmatación

\footnotetext{
${ }^{1}$ Los macrorrestos están a la espera de su publicación en detalle por Leonor Peña Chocarro (Grupo de investigación Paleoeconomía y Subsistencia de las Sociedades Preindustriales, Instituto de Historia, CSIC).
}

del Foso ZS (Zanja Sur) II de la Fase I, evidenciando su posterior cronología. Las formas de los tipos vasculares son esféricas con engobes a la almagra y labio de sección redondeada. Algunos ejemplares están pintados. Esta fase se atribuye a un Neolítico Reciente incluido en la primera mitad del IV milenio cal AC.

La Fase III correspondería al inicio de la Edad del Cobre, identificada en la zona central y septentrional del cerro. Sería la ocupación más representativa por la abundancia de vestigios, depósitos antropológicos y animales incluidos. Hay 108 estructuras de distinta tipología, en su mayoría de planta circular. Destacan los vasos, cazuelas y fuentes carenadas, así como una producción lítica basada en la obtención de láminas prismáticas. Dichas características tecnotipológicas, unidas a dataciones absolutas aún inéditas, sitúan esta fase hacia el último tercio del IV milenio cal AC.

La Fase IV queda definida por una única tumba con un ajuar encuadrable en el Calcolítico Pleno/Final. Integra seis vasos completos y un puñal metálico de lengüeta, elemento presente en contextos funerarios asociados al Horizonte Campaniforme del Valle del Guadalquivir.

\section{LA FASE I DE GRAÑENA BAJA}

\subsection{Estructuras}

La sincronía entre las estructuras se estableció a través de la caracterización de los artefactos recuperados y de dataciones radiocarbónicas. Dos "zanjas" que parecen conformar un gran foso segmentado de dirección este-oeste en la zona sur del cerro constituyen el rasgo más sobresaliente. El segmento oriental, ZS I, se excavó en su totalidad. El trazado, ligeramente curvo y sección en "U". tenía $48 \mathrm{~m}$ de longitud, $2,10 \mathrm{~m}$ de potencia máxima y entre 3,80 y $5,80 \mathrm{~m}$ de anchura. El segmento ZS II presentaba en planta un trazado recto con sección en artesa. La anchura alcanzaba 7 $\mathrm{m}$ medida en la superficie y $3,50 \mathrm{~m}$ en el fondo. La potencia variaba entre 1,86 y $1,50 \mathrm{~m}$. Se documentaron solo $15 \mathrm{~m}$ del recorrido del segundo segmento al quedar interrumpido por el límite occidental del área intervenida. Desconocemos, pues, la extensión original y planta completa de la estructura. Un espacio de $6 \mathrm{~m}$ de anchura abierto entre las zanjas permitía el acceso al interior (Fig. 2).

El registro estratigráfico permite inferir que ambos fosos fueron colmatados en un lapso temporal breve. El material arqueológico más destacable es la cerámica de gran homogeneidad tipológica. En su mayoría estaba concentrada en contacto directo con la base del foso. Detectamos múltiples fragmentos con fracturas no erosionadas correspondientes a vasos reconstrui- 


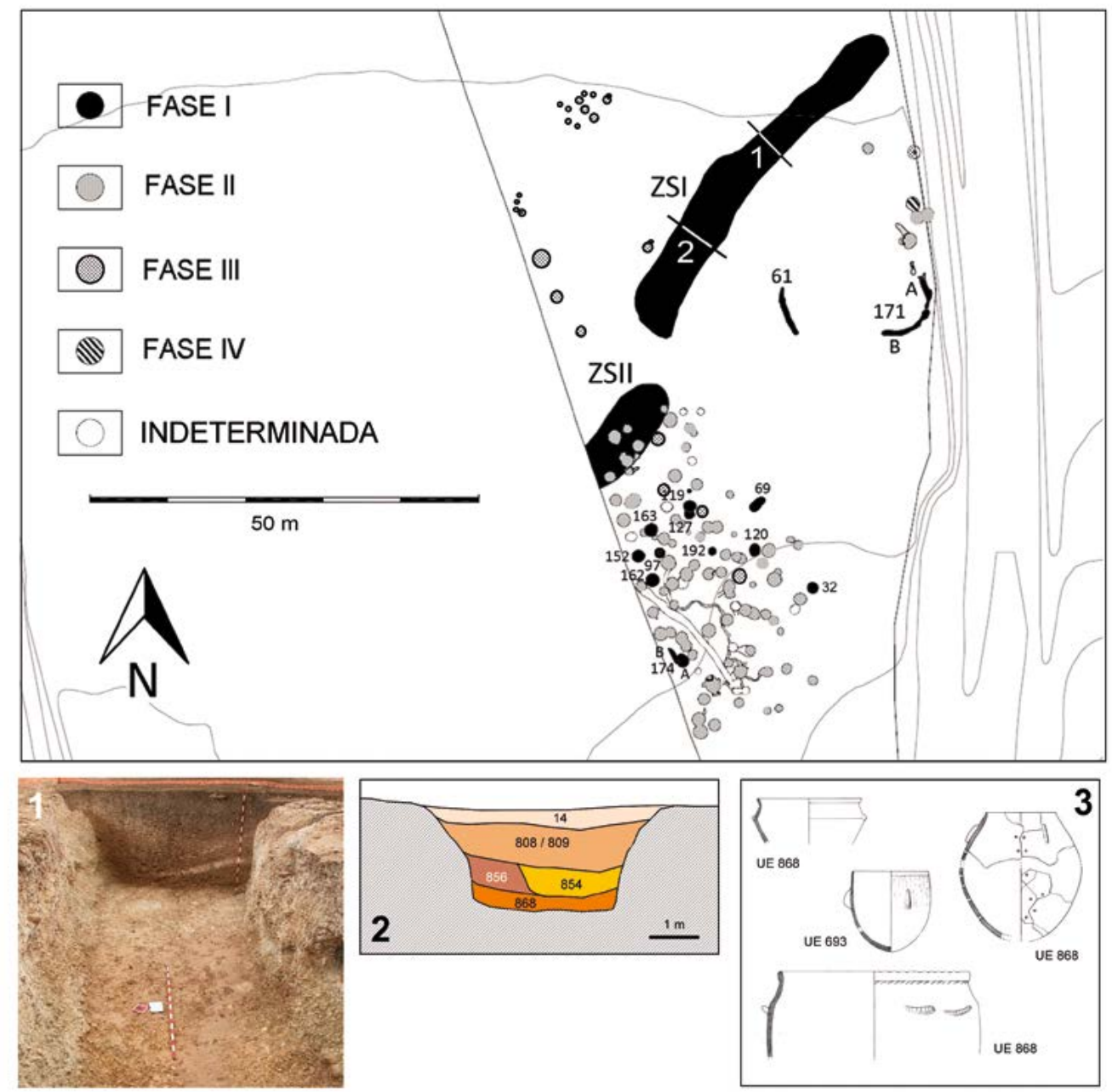

Fig. 2. Planimetría del sector meridional de Grañena Baja (Jaén), mostrando las estructuras negativas circulares y en forma de zanja. Se indican las dos secciones estratigráficas efectuadas en el foso segmentado Zanja Sur I: 1. en el sector central y 2. en el meridional, reproduciéndose algunas de las formas cerámicas (3) halladas en sus Unidades Estratigráficas inferiores (1 y 2 en color en la versión electrónica).

bles. Los niveles medios y superficiales constituían por lo general estratos estériles de grandes espesores (a veces de hasta $1 \mathrm{~m}$ de potencia). Estaban compuestos por paquetes heterométricos con predominio de grava y cantos de diverso tamaño, procedentes del sustrato del sitio.

Una serie de estructuras de difícil interpretación, entre ellas un complejo formado por "zanjas menores", se localizaron al sur de la ZS I. Un par, 171 A y B, se hallaban colmatadas en gran parte por cantos rodados de distinta granulometría y por escasos materiales cerámicos (Fig. 3F). Más al oeste la estructura E-61 de 6,60 m de longitud total tenía un acceso en rampa que conducía a un espacio de mayor amplitud con paredes ligeramente acampanadas. Lajas de arenisca, fijadas a la pared mediante tierra margosa compactada también presente en el suelo, revestían el inicio del corredor. El interior de dicha estructura mostraba importantes alteraciones térmicas (Fig. 3A-C).

Sobre la pared septentrional de la estructura singular E-69 se documentó un ortostato de arenisca in situ, así como algunas lajas del mismo material fracturadas y hundidas en el interior hacia el centro, quizás parte de una cubierta. El área de acceso se hallaba colmatada por cantos de tamaño desigual. La cámara contenía algunos restos de lajas de la cubierta y algunos fragmentos cerámicos atípicos (Fig. 3D-E).

Finalmente, hacia el extremo suroeste de área intervenida, se detectaron diez estructuras negativas, en su mayoría de planta circular. Estas proporcionaron un conjunto muy reducido de materiales cerámicos y líticos, cuyos caracteres tecnotipológicos han 


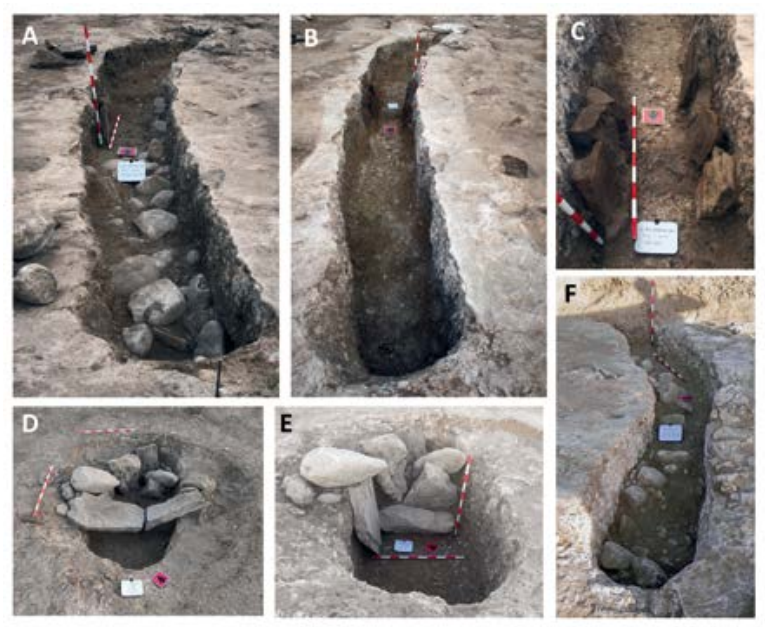

Fig. 3. Estructuras (E) de la Fase I en Grañena Baja (Jaén): A-C E-61 con termoalteración; D-E E-69 circular con elementos pétreos de función indeterminada; F, E-171 con disposición en curva (fotografias de E. Conlin, en color en la versión electrónica).

servido, como en los casos anteriores, para adscribirlos a esta fase.

\subsection{La cerámica}

Se ha recuperado un total de 6160 piezas cerámicas, de los que 976 son bordes o elementos que han permitido reconstruir la forma completa (15,8 \%) (Fig. 4). Para su clasificación hemos seguido análisis similares de conjuntos cerámicos de la Prehistoria reciente ibérica (García Borja y Pérez 2012; García Borja 2017), adaptándolos a las particularidades de la cultura material. El resultado ha sido la distinción de cuatro tipos básicos, repartidos en distintos porcentajes (Tab. 1):

\begin{tabular}{|l|c|c|}
\hline \multicolumn{1}{|c|}{ Tipo } & N & \% ID \\
\hline Tipo I & 745 & 67.6 \\
\hline Tipo II.1 & 147 & 13.3 \\
\hline Tipo II.2 & 119 & 10.8 \\
\hline Tipo III & 29 & 2.6 \\
\hline Tipo IV & 62 & 5.6 \\
\hline Total id. & $\mathbf{1 1 0 2}$ & $\mathbf{1 7 . 9}$ \\
\hline No identificado & $\mathbf{5 0 5 8}$ & $\mathbf{8 2 . 1}$ \\
\hline Total fragmentos & $\mathbf{6 1 6 0}$ & - \\
\hline
\end{tabular}

Tab. 1. Total de fragmentos cerámicos atribuidos a tipos determinados y no atribuidos en Grañena Baja (Jaén).
Tipo I: Formas carenadas. Por regla general son recipientes troncocónicos de morfología compuesta. Tienen un perfil angular marcado, o carena, y un profundo fondo cóncavo, que podría haberse realizado a partir de un molde parcial. Su factura suele ser excelente, en comparación con la de otros tipos. Emplean pastas muy depuradas y compactas con desgrasantes apenas visibles. Sus paredes son delgadas, a veces de menos de $5 \mathrm{~mm}$. Dominan los acabados bruñidos. Comparten un labio ligeramente engrosado al exterior, alargado y en resalte, describible como borde reforzado o "en pestaña", exvasado o en forma recta. Carecen de decoración. Sí puede haber algunos pequeños mamelones sobre la carena o a su altura que es media o alta. Los diámetros de la boca varían entre 10 y 35 $\mathrm{cm}$. Es el tipo mejor representado: $67 \%$ del total de formas reconocibles (Fig. 5).

Tipo II: Formas ovoides. Suponen un conjunto relativamente tosco de recipientes en comparación con los anteriores. Las formas son globulares de perfil ovoide o de paredes rectas, aunque también hay algunas abiertas y de paredes convergentes. El aspecto de algunas superficies apunta claramente a su fabricación a partir de un molde externo. Las pastas suelen ser de tonalidad parda, textura harinosa o escamosa y superficies poco cuidadas con tacto rugoso, debido a tratamientos que abarcan desde un simple alisado a un escobillado parcial. Se repite en la mayoría de los recipientes el borde reforzado mediante un engrosamiento externo del labio.

Este grupo cuenta con abundantes motivos decorados, en su mayoría impresos. La decoración sigue un ritmo constante en una única línea que cubre el límite entre el labio y la pared. Se reconocen secuencias de digitaciones y ungulaciones, impresiones realizadas con materia vegetal (haces de tallos) o materias duras (punzones o elementos articulares de hueso), asociadas con frecuencia a labios dentados. Algunos de estos ejemplares presentan asas modeladas en forma de lengüeta vertical, mientras otros incluyen en algún caso lengüetas en oreja horizontal. Contamos con un solo ejemplar con engobe a la almagra de buena calidad y superficie bruñida (Fig. 6: 4).

Los tamaños de los recipientes con cuerpo ovoide van desde pequeño y mediano (subtipo 1) a gran tamaño (subtipo 2) (Fig. 6: 9-12). Los diámetros de la boca del subtipo 1 varían entre 13 y $28 \mathrm{~cm}$. Los del subtipo 2 tienen de 20 a $40 \mathrm{~cm}$ de diámetro en la boca) $\mathrm{y}$, por lo general, cocción reductora con adición de desgrasantes gruesos. Este subtipo se caracteriza por un mayor desarrollo del denominado borde reforzado, similar a una banda engrosada al exterior. Su sección rectangular o triangular está remarcada por los motivos decorados. Desconocemos el perfil completo de estos 
TIPO I.

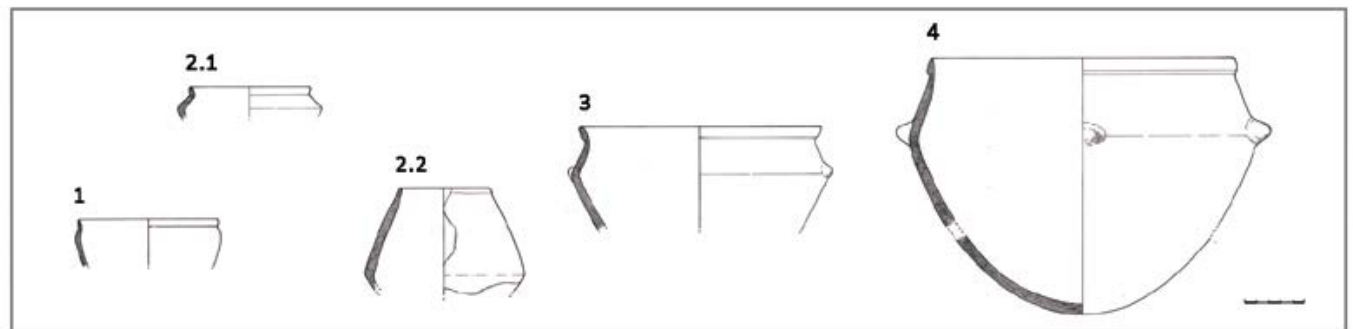

TIPO II.

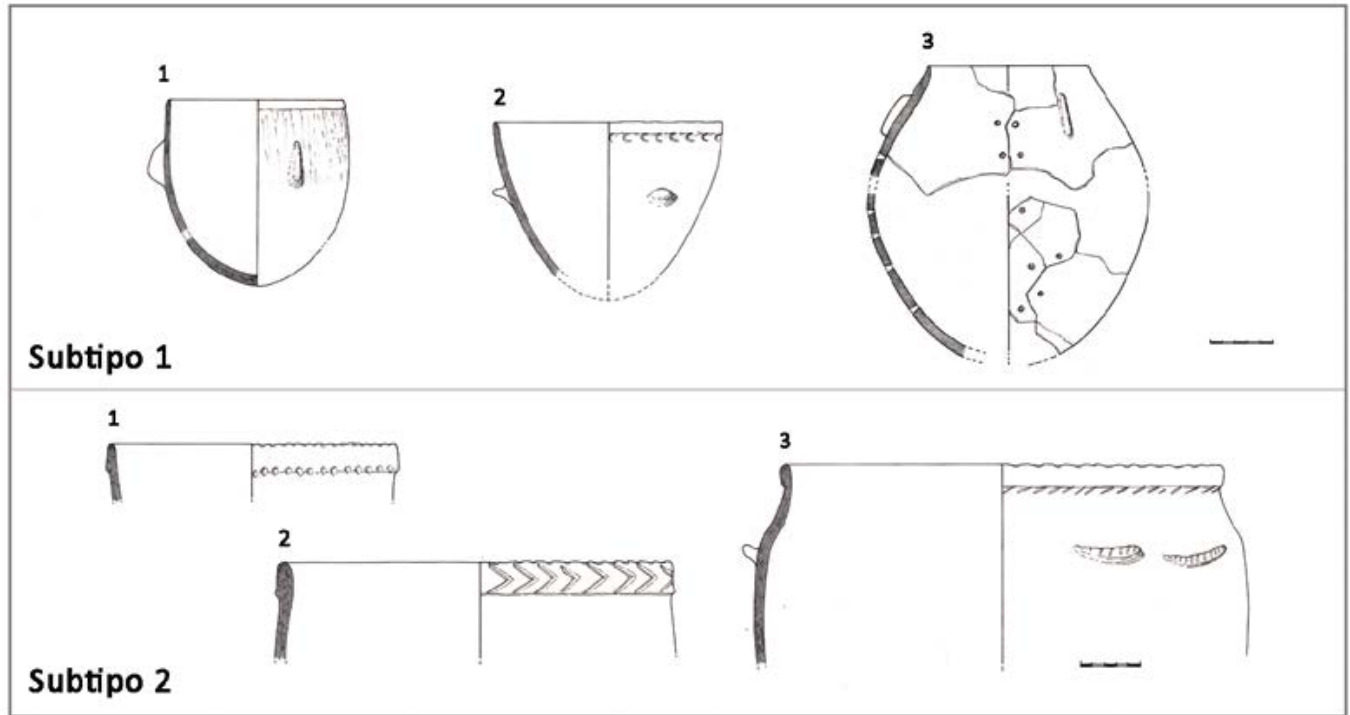

TIPO III.

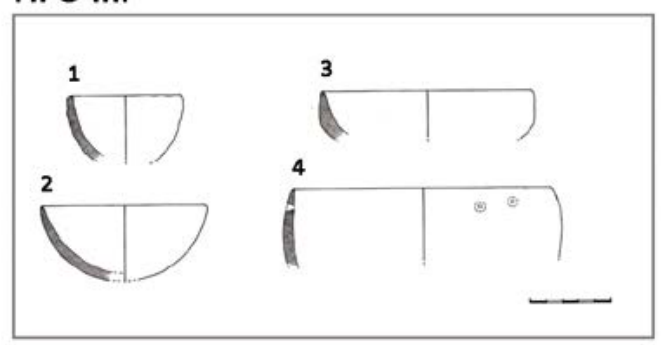

TIPO IV.

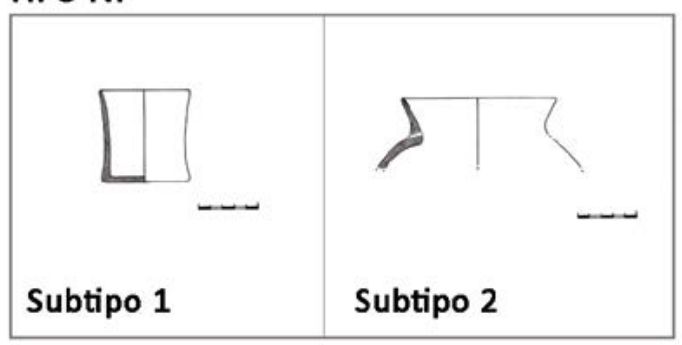

Fig. 4. Tipología diseñada para las formas cerámicas de la Fase I en Grañena Baja (Jaén), según dibujo de E. Conlin.

recipientes que contarían, probablemente, con paredes de tendencia recta y fondo cóncavo.

Tipo III. Cuencos. Fundamentalmente de tipo semiesférico y de casquete esférico con diámetros entre 7 y $16 \mathrm{~cm}$ y superficies alisadas. Destaca un solo fragmento decorado a base de líneas horizontales incisas que cubren la superficie exterior.

Tipo IV: Diversos. Este grupo integra dos recipientes. El subtipo 1 es un vaso cilíndrico de paredes ligeramente cóncavas y base plana. Mide 7,5 $\mathrm{cm}$ de diámetro y $8 \mathrm{~cm}$ de altura. Su factura es si- milar a las piezas del Tipo I. El subtipo 2 está definido por dos fragmentos de vaso globular de cuello estrangulado y borde exvasado, realizado en pasta muy depurada. El cuello y el cuerpo presentan motivos esgrafiados conformando zigzags o escaleriformes.

La cerámica decorada constituye el 5,5\% del total de fragmentos (Tab. 2). Entre las impresiones distinguimos series realizadas con un instrumento indeterminado, quizás de tipo vegetal y con ligero arrastre, así como ungulaciones y digitaciones. La decoración incisa se 


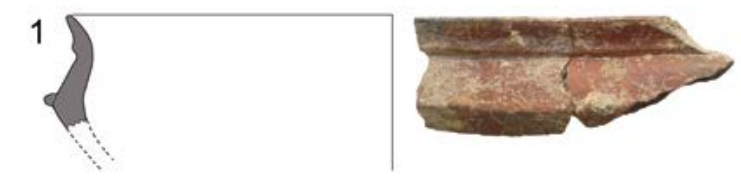

2

\begin{tabular}{|l|c|}
\hline \\
\hline
\end{tabular}
media, según foto y dibujo de E. Conlin (en color en la versión electrónica).
3
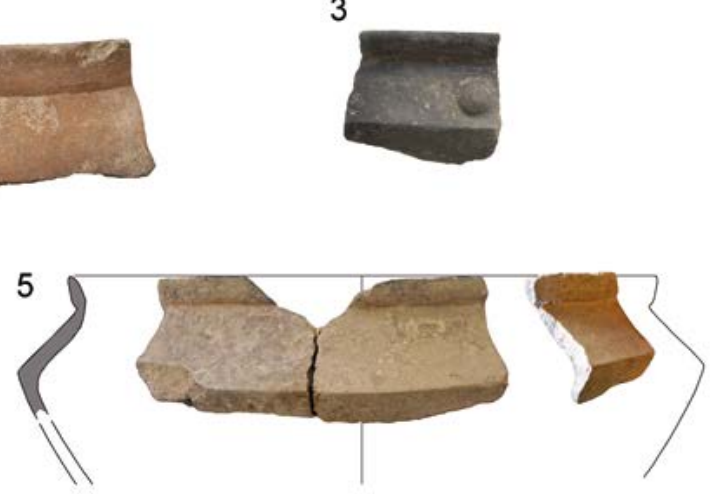

6

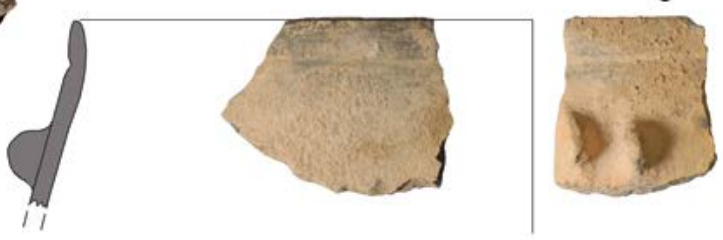

Fig. 5. Zanja Sur de Grañena Baja (Jaén), Fase I. Selección de fragmentos cerámicos del denominado Tipo I, formas compuestas de carena

Tab. 2. Porcentaje de fragmentos cerámicos decorados de la Fase I en Grañena Baja (Jaén).

reduce a series de incisiones cortas y los motivos esgrafiados describen trazos quebrados en zigzag.

Entre los elementos cerámicos no vasculares hay hasta 51 de forma circular y reciclados. Se hicieron

Trab. Prehist., 77, N. ${ }^{\circ}$ 1, enero-junio 2020, pp. 30-47, ISSN: 0082-5638

https://doi.org/10.3989/tp.2020.12245 tallando y recortando fragmentos de pared. Tienen unos $3-5 \mathrm{~cm}$ de diámetro y todos carecen de perforación.

\subsection{Los artefactos líticos}

El conjunto lítico tallado se compone de 187 piezas. La metodología seguida es la habitual en otros trabajos: un examen petrológico y una descripción tipológica y tecnológica. El estudio petrológico interpreta las facies sedimentarias mediante microscopía de altos aumentos e identificación de microfósiles (Morgado y Lozano 2014: 125-126) y el tecnotipológico parte del concepto de cadena operativa (Morgado et al. 2011: 146).

Las fuentes principales de materia prima son las zonas montañosas ubicadas en la Cordillera Bética. En la estrategia de abastecimiento, apreciamos una clara selección de la materia prima al comparar el cómputo global de los elementos laminares. Entre los que re- 


\begin{tabular}{|l|r|r|r|c|}
\hline \multicolumn{1}{|c|}{ Mat Primas } & Real & Relativo & Láminas (Real) & Láminas (Relativo) \\
\hline Sílex Form. Milanos (peletoidal/oolítica) & 58 & 31.01 & 47 & 59.49 \\
\hline Sílex Form. Milanos (textura wackestone) & 45 & 24.06 & 18 & 22.78 \\
\hline Sílex peletoidal restos orgánicos & 2 & 1.06 & 1 & 1.26 \\
\hline Sílex plataforma con oolitos (local) & 52 & 27.8 & - & - \\
\hline Sílex peloides dendritas piroluxita & 1 & 0.53 & 1 & 1.26 \\
\hline Sílex textura mudstone & 4 & 2.14 & - & - \\
\hline Sílex de radiolarios (radiolarita) & 5 & 2.67 & - & - \\
\hline Cuarcita & 3 & 1.6 & 2 & 2.53 \\
\hline Jaspe & 1 & 0.53 & - & - \\
\hline Indeterminable (alt. térmica) & 16 & 8.55 & $\mathbf{9 9}$ & $\mathbf{2}$ \\
\hline N Total & $\mathbf{1 8 7}$ & $\mathbf{9 9 . 9 5}$ & $\mathbf{7 9}$ & $\mathbf{9 9 . 9 8}$ \\
\hline
\end{tabular}

Tab. 3. Porcentaje de materias primas usadas para la producción de soportes líticos en Grañena Baja (Jaén).

quirieron unas cualidades específicas (Tab. 3) faltan las materias primas propias de los depósitos secundarios circundantes: el sílex de la Formación Milanos domina en dicho conjunto.

La proporción de lascas y láminas es muy equilibrada entre los elementos tallados (Tab. 4). Sin embargo, considerando estos grupos respecto al material retocado, dominan las láminas (49) sobre los soportes tipo lasca (19). Llama la atención la ausencia de núcleos, atribuible a una escasa presencia de actividades de talla in loco. La existencia de lascas con superficies naturales, corticales, rodadas o fruto del reciclaje de antiguos objetos tallados, señalaría el aprovechamiento de recursos locales, en su mayoría pequeños nódu-

\begin{tabular}{|c|c|c|c|}
\hline Elementos & \multicolumn{2}{|c|}{$\mathbf{N}$} & $\%$ \\
\hline Nódulo & \multicolumn{2}{|c|}{1} & 0.53 \\
\hline Chunks & \multicolumn{2}{|c|}{14} & 7.49 \\
\hline Tectofracto & \multicolumn{2}{|c|}{1} & 0.53 \\
\hline Debris & \multicolumn{2}{|c|}{12} & 6.42 \\
\hline Lascas & 49 & \multirow{4}{*}{79} & \multirow{4}{*}{42.25} \\
\hline Lascas-laminares & 9 & & \\
\hline Lasquitas & 2 & & \\
\hline Lascas retocadas & 19 & & \\
\hline Láminas & 30 & \multirow{2}{*}{79} & \multirow{2}{*}{42.25} \\
\hline Láminas Ret & 49 & & \\
\hline Astilla & \multicolumn{2}{|c|}{1} & 0.53 \\
\hline Total & \multicolumn{2}{|c|}{187} & 9.98 \\
\hline
\end{tabular}

Tab. 4. Tipos de productos líticos transformados en Grañena Baja (Jaén). los extraídos de los depósitos fluviales. La talla de estos recursos pudo ejecutarse en el propio lugar, con núcleos de escasa preparación, utilizando las extracciones precedentes como planos de percusión. Dicha talla, expeditiva y de baja inversión técnica, implicaría la obtención ocasional de productos cuyas dimensiones determinó la naturaleza de la materia prima.

Un segundo bloque agrupa un método de talla laminar, que exige cierta destreza en la cadena operativa. Desafortunadamente, este sólo puede ser deducido a partir de los productos de plena elaboración hallados. La práctica totalidad son láminas de secciones trapezoidales regulares (Fig. 7), que implican una gestión de núcleos de progresión frontal, diferente de la presente en núcleos carenados o carenoides del Neolítico Antiguo, cuyas láminas muestran secciones triangulares, trapezoidales irregulares o poligonales (Morgado y Pelegrin 2012). Dicha gestión supone un cambio cualitativo que favorece la estandarización de la producción laminar. La disposición de las extracciones de estas láminas de sección prismática (Binder et al. 2012) avanza otra de las características de las producciones laminares del IV y III milenio cal AC, la talla mediante un esquema de gestión 2-1-2' que caracteriza sus secciones trapezoidales. La mayoría de las láminas (20 de 23) presentan talones lisos acompañados de la abrasión frontal de las cornisas como procedimiento previo a la extracción, seguidos de lejos por dos facetados y uno diedro. Dicha característica aparece en todas las producciones del Neolítico Antiguo (Afonso 1993; Vera 1997; Martínez Fernández et al. 2010; Morgado y Pelegrin 2012; Martínez Sánchez y Vera 2017a). Sin embargo, a diferencia de lo que viene a ser habitual en los conjuntos de dicho período, estas láminas carecen de trata- 


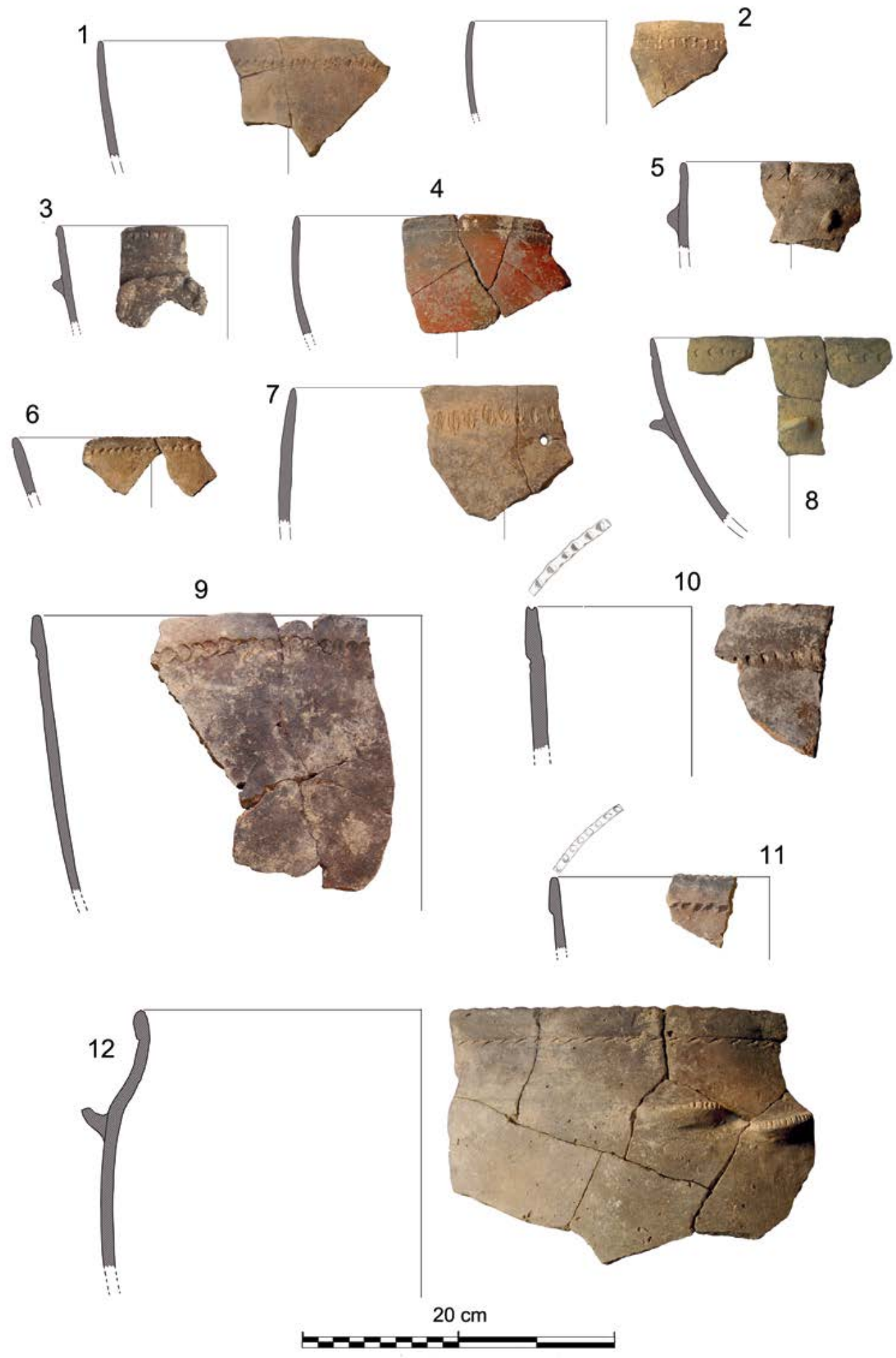

Fig. 6. Zanja Sur de Grañena Baja (Jaén), Fase I. Selección de fragmentos cerámicos del denominado Tipo II, Subtipo 1 (1-8) y Subtipo 2 (9-12), formas de gran tamaño, según foto y dibujo de E. Conlin (en color en la versión electrónica).

Trab. Prehist., 77, N. ${ }^{\circ}$, enero-junio 2020, pp. 30-47, ISSN: 0082-5638

https://doi.org/10.3989/tp.2020.12245 


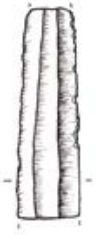

$\leftrightarrow 1$

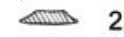

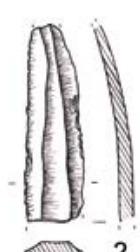

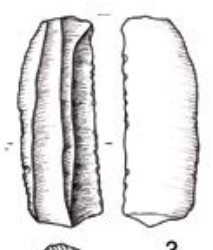

3
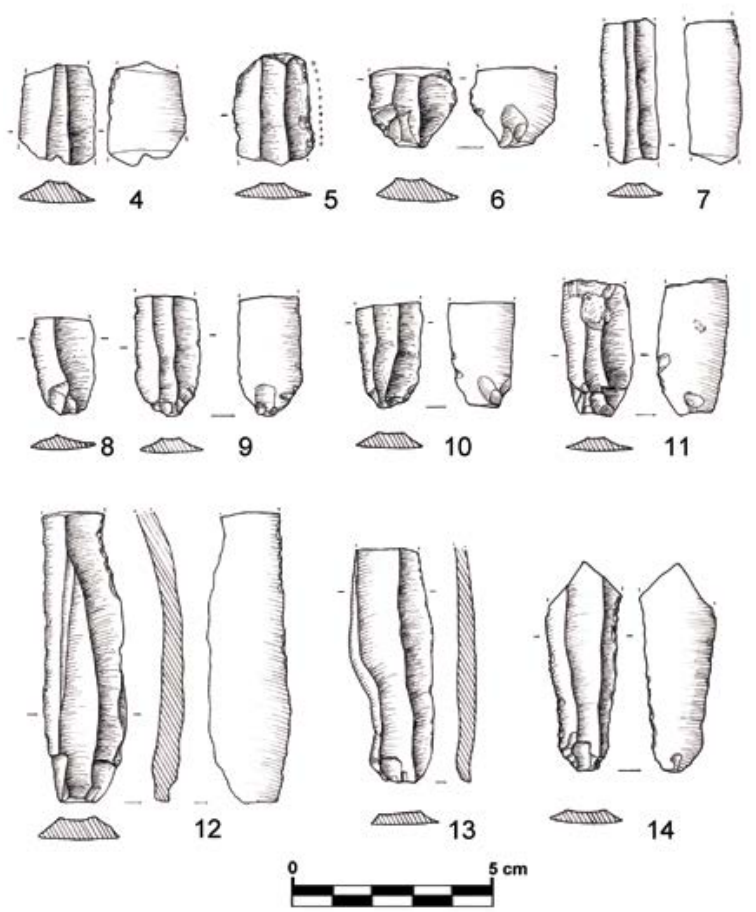

Fig. 7. Grañena Baja (Jaén), Fase I. Láminas de sílex sin retocar, según dibujo de E. Conlin.

miento térmico, mostrando una ruptura con la tradición anterior.

La presencia de talones lisos espesos, bulbos desarrollados y prominentes, así como la observación de esquirlas parásitas en el eje de la dirección de la talla, señalaría el uso de la percusión indirecta (Pelegrin 2006, 2012). A ello apunta también la falta de regularidad que caracterizan bordes y aristas totalmente paralelos, así como el arqueamiento reflejado en el perfil de las láminas. Esta percusión debió hacerse con elementos orgánicos apoyados sobre una plataforma plana, lo que tendría su reflejo en los talones lisos. Otras láminas, más escasas y dotadas de una alta regularidad de perfil y borde indicarían el uso de la técnica de presión, si bien siguiendo el mismo proceso de preparación de los núcleos y las extracciones. La cadena operativa implica el método de talla de núcleos prismáticos de progresión frontal y el recurso mayoritario a la percusión indirecta y en menor medida a la presión.

Entre los útiles retocados dominan los realizados sobre lámina, restringiéndose a retoque discontinuo de uso y retoque abrupto marginal. En tercer lugar, aparecen los denticulados y muescas. Por último, las truncaduras retocadas sobre lámina se unen de manera singular a la presencia de un geométrico y a alguna lámina de dorso. Ello nos indica un dominio del retoque abrupto que permitiría el enmangue de estos filos en favor nuevamente de la utilización de otros sin alta modificación secundaria. Las características tipológicas del geométrico lo alejan de otros elementos similares propios del Neolítico Antiguo (Martínez Fernández et al. 2010; Martínez Sánchez y Vera 2017a) (Fig. 8, Tab. 5).

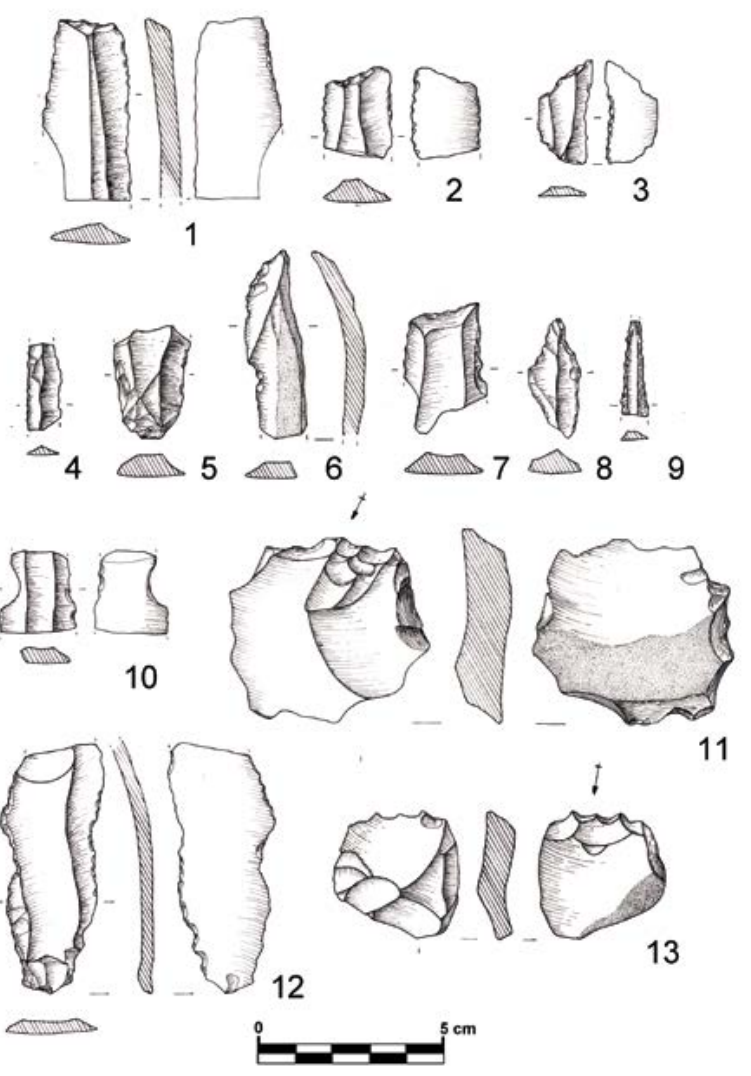

Fig. 8. Grañena Baja (Jaén), Fase I. Artefactos tallados retocados: 1-2. truncaduras; 3 . geométricos; 4-7. láminas retocadas; 8-9. taladro y perforador; 10. muesca; 11-13. denticulados, según dibujo de E. Conlin. 


\begin{tabular}{|l|r|c|}
\hline \multicolumn{1}{|c|}{ Tipos } & N & Porcentaje \\
\hline Lascas retocadas & 2 & 2.94 \\
\hline Láminas ret uso & 15 & 22.05 \\
\hline Láminas ret marginal & 11 & 16.17 \\
\hline Muescas & 8 & 11.76 \\
\hline Denticulados & 13 & 19.11 \\
\hline Truncaduras & 7 & 10.30 \\
\hline Láminas dorso & 2 & 2.94 \\
\hline Geométricos & 1 & 1.47 \\
\hline Perforadores y taladros & 6 & 8.82 \\
\hline Buril & 1 & 1.47 \\
\hline Astillado & 1 & 1.47 \\
\hline Diverso (abrupto distal cóncavo) & 1 & 1.47 \\
\hline Total & $\mathbf{6 8}$ & $\mathbf{9 9 . 9 7}$ \\
\hline
\end{tabular}

Tab. 5. Porcentaje de soportes líticos de la Fase I en Grañena Baja (Jaén).

\subsection{Los restos de fauna}

El estudio de los restos de fauna ha seguido la metodología descrita en trabajos recientes (Martínez Sánchez 2017: 99), si bien la mala conservación del material ha limitado enormemente el alcance de los resultados.

Se ha considerado como Fase 1 todo el material documentado en los rellenos de los fosos ZS I y II en sus distintos sectores. Son 590 restos cuya conservación es muy deficiente debido a fragmentación diagenética y a corrosión biogeoquímica. Como resultado el número de elementos identificables se ha reducido a 82 restos de mamíferos identificables a nivel de género y especie (Tab. 6). Los elementos anatómicos resultan tan dispares y a la vez escasos que, a excepción del cerdo (con dos individuos determinados en función de los arcos ventrales de dos CV1/atlas diferentes) y dos posibles M1 inferiores izquierdos de caprino doméstico (posiblemente oveja y que harían igualmente dos individuos), el resto de las especies podrían ser atribuidas a un solo individuo. Sin embargo, el hecho de que el bovino doméstico parezca erigirse como el principal taxón determinado apuntaría, quizás, a una creciente importancia de dichos animales a lo largo del V milenio, como se ha propuesto para otros enclaves del Mediterráneo ibérico (Liesau y Morales 2012: 123). Dentro del conjunto de macromamíferos no determinados incluiríamos équidos, a partir de los tres molares identificados del conjunto general de esta fase, correspondientes a un único individuo adulto compatible con caballo, previsiblemente de rango salvaje.

\begin{tabular}{|c|c|c|c|c|}
\hline FASE 1 & $\begin{array}{l}\text { NRD/ } \\
\text { NISP }\end{array}$ & $\%$ & PR & NMI \\
\hline Bos taurus & 41 & 6.95 & 948.6 & 1 \\
\hline Sus scrofa & 15 & 2.54 & 70.2 & 2 \\
\hline Ovis/Capra & 13 & 2.20 & 51.7 & 1 \\
\hline Ovis aries & 16 & 0.34 & 6 & 2 \\
\hline Capra hircus & 1 & \begin{tabular}{l|l}
0.17 \\
\end{tabular} & 1 & 1 \\
\hline Equus caballus & 3 & 0.51 & 52 & 1 \\
\hline Cervus elaphus & 5 & 0.85 & 190 & 1 \\
\hline Canis familiaris & 2 & 0.34 & 9.7 & 1 \\
\hline Macromamíferos & 229 & 38.81 & 1089.7 & - \\
\hline Mesomamíferos & 147 & 24.92 & 225.5 & - \\
\hline $\begin{array}{l}\text { Meso- } \\
\text { macromamiferos }\end{array}$ & 11 & 1.86 & 21 & - \\
\hline Mam. no det. & 108 & 18.31 & 124.7 & - \\
\hline $\begin{array}{l}\text { Margaritifera } \\
\text { auricularia }\end{array}$ & 5 & 0.85 & 74.62 & 2 \\
\hline $\begin{array}{l}\text { Potomida } \\
\text { littoralis }\end{array}$ & 3 & 0.51 & 19.3 & 1 \\
\hline Unio delphinus & 1 & 0.17 & 2 & 1 \\
\hline Unionoida & 4 & 0.68 & 9.6 & - \\
\hline Total & 590 & - & 2895.62 & - \\
\hline
\end{tabular}

Tab. 6. Desglose taxonómico de vertebrados y moluscos, por especie y grupo en Grañena Baja (Jaén). NRD/NISP, número de restos determinados; \%, porcentaje de restos identificados; PR, peso de los restos; NMI, número mínimo de individuos estimado.

\subsection{Restos óseos humanos}

Los restos humanos correspondientes a la Fase I, una acumulación de huesos desarticulados, se registraron exclusivamente en el foso ZS II (UE 955) hacia el centro de esta estructura y cerca del fondo. Pertenecen a un mínimo de cinco sujetos diferentes, dos masculinos, uno femenino, un adulto indeterminado y un subadulto de 6-7 años. Dada la presencia de falanges, tarsales y carpales en dicho contexto, cabría hablar bien de un depósito descompuesto in situ y sujeto a movimiento y extracción de elementos, o bien de uno puramente secundario ${ }^{2}$. Junto a los restos óseos se localizaron elementos artefactuales, como una falange de ciervo transformada por abrasión, un vaso cilíndrico de base plana y un cuenco decorado a base de líneas incisas horizontales (Fig. 9).

\footnotetext{
${ }^{2}$ Guijo Mauri, J. M. 2016: Memoria antropológica de las actuaciones en Grañena. Junta de Andalucía, Jaén; pág 136.
} 

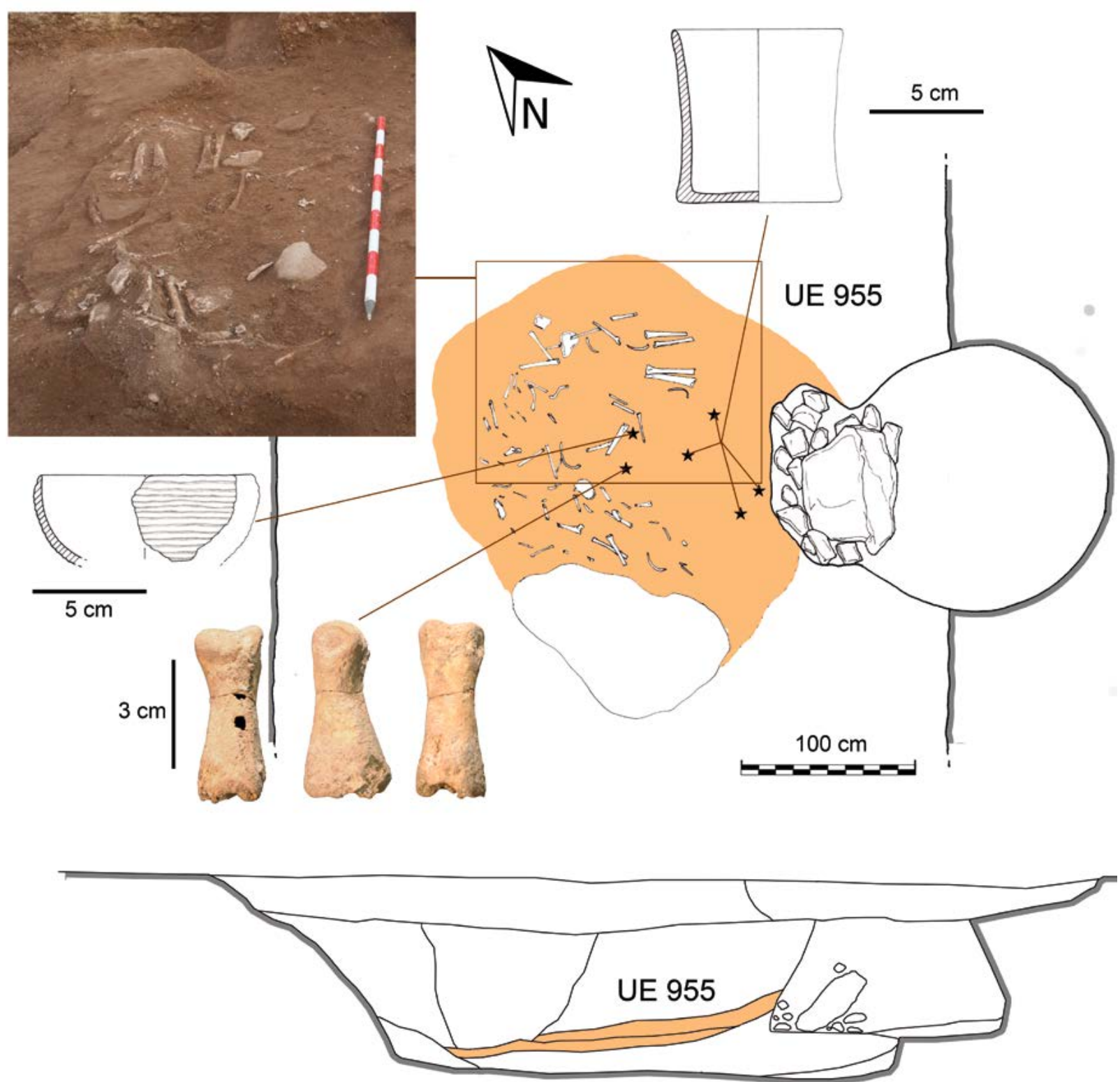

Fig. 9. Vista en detalle de los depósitos de restos humanos asociados al foso Zanja Sur de Grañena Baja (Jaén), Fase II (Unidad Estratigráfica 955), y artefactos asociados, según dibujo de E. Conlin y R. M. Martínez.

\subsection{Cronología}

Para la datación de dicha fase fueron seleccionados dos elementos óseos correspondientes a bovino doméstico (Bos taurus), hallados en las mismas condiciones deposicionales. Del foso ZSI (UE 693) se seleccionó un fragmento de metatarso y del foso ZSII (UE 918) un molar.

Los resultados obtenidos destacan por su concordancia. Son dos dataciones estadísticamente idénticas hechas en dos laboratorios diferentes (Tab. 7) y asociadas al nivel basal de ambos fosos, 


\begin{tabular}{|l|l|l|c|l|l|l|}
\hline Estructura & \multicolumn{1}{|c|}{ UUEE } & \multicolumn{1}{c|}{ Sigla } & BP Date & \multicolumn{1}{c|}{ Material } & cal AC 68.2 \% & cal AC 95.4 \% \\
\hline ZSII & 918 & Beta-459923 & $5610 \pm 30$ & Metápodo Bos taurus & $4464-4371$ & $4498-4361$ \\
\hline ZSI & 693 & CNA-2897 & $5614 \pm 36$ & Molar Bos taurus & $4487-4373$ & $4518-4359$ \\
\hline
\end{tabular}

Tab. 7. Dataciones radiocarbónicas obtenidas para la Fase I de Grañena Baja (Jaén) (calibración, curva atmosférica de Reimer et al. 2013).

de donde procede la mayor parte de la cultura material recuperada. Relacionan el inicio de la colmatación de ambas estructuras con el tercer cuarto del $\mathrm{V}$ milenio (c. $4450 \mathrm{cal} \mathrm{AC})^{3}$, evento que cabe situar próximo a esta primera fase de ocupación, no pudiendo precisar si aquel resultaría sincrónico o levemente posterior. Así, y considerando la composición de los rellenos que colmataban la estructura, podríamos situar con bastante seguridad la sucesión de eventos que encadenan su construcción y amortización definitiva dentro de un lapso cronológico relativamente corto.

\section{DISCUSIÓN}

\subsection{Una cultura material diferenciada}

Del repertorio de formas cerámicas documentadas en Grañena Baja I parece desprenderse una ruptura con el mundo anterior del Neolítico Antiguo, donde predominan formas de aspecto muy diferente. Junto a estas destaca un amplio repertorio de decoraciones incisas impresas y modeladas, así como un recurso a elementos de prehensión y suspensión, propios del Neolítico Andaluz (Camalich y Martín 2013: 105).

Esta nueva tradición tecnológica no parece del todo desconocida en otros sitios arqueológicos del mediodía de la península ibérica, si bien podría haber pasado desapercibida por su errónea identificación con producciones de cronología más reciente intrusivas en la secuencia. Tanto las formas del Tipo I, bitroncocónicas y de notable carena, como las formas ovales del Tipo II, ambas caracterizadas por sus paredes de escaso grosor y borde reforzado, están presentes en las antiguas excavaciones de la Cueva de la Carigüela (Piñar Granada) en el área G, a partir del estrato IX, siendo abundantes en los estratos VIII y VII, y enrareciéndose a partir del VI (Navarrete 1976: II, LAM LXXXVIII, XCV, CIV, CVI y CXI). Igualmente formas similares se observan en la Cueva de Nerja, Sala de la Mina (Corte NMB, niveles 6 y 7 atribuidos por Pellicer al Neolítico Reciente; NM, 4 y 5 en los trabajos de Jordá, atribuidos al Neolítico Medio I) (Pellicer y cal AC.

3 Todas las fechas en el artículo, salvo indicación en contrario, son

Trab. Prehist., 77, N. ${ }^{\circ}$ 1, enero-junio 2020, pp. 30-47, ISSN: 0082-5638

https://doi.org/10.3989/tp.2020.12245
Acosta 1997: figs. 30, 31 y 34; García Borja et al. 2014: figs. 6 y 17), la Cueva de la Dehesilla en fases del Neolítico Medio y Reciente (Pellicer y Acosta 1990), y en la Cueva del Toro (Subfase IIIB), incluidas dentro del último cuarto del $\mathrm{V}$ milenio (Martín et al. 2004: figs. 46 y 51). Desprovistos de contexto arqueológico, se ha dado a conocer un conjunto similar procedente de la Cueva del Perro (Periana, Málaga) (Fernández 2013: fig. 11 y 12).

Este tipo de formas también podrían identificarse en otros enclaves al aire libre adscritos al V milenio, emplazados en Córdoba y Huelva (Gavilán y Escacena 2009: fig. 13; Morgado et al. 2015: 42; ${ }^{4}$ ). Por su parte, en el sitio datado en el tránsito del V al IV milenio de Campo de Hockey, San Fernando, Cádiz, se observan formas compuestas, incluyendo lengüetas verticales y un característico surco continuo bajo el borde (Vijande et al. 2015: 157). Dicho rasgo, casi una franja que separa un borde reforzado reducido a su mínima expresión (denominado sulco abaixo do bordo en la bibliografía portuguesa), caracteriza las cerámicas atribuidas a estos momentos en el resto de la franja atlántica del suroeste peninsular (costa alentejana y Estremadura), presentes en los enclaves al aire libre de Pena d'Agua, y Monte da Foz (Neves 2015).

En el área central mediterránea ibérica (Final del Neolítico Medio I, inicios del II, o Neolítico IIA/IC siguiendo las divisiones empleadas en dicho territorio), cerámicas de factura fina, con el característico borde reforzado y en ocasiones carena media, comparten cronología con cerámicas esgrafiadas, las cuales parecen representar una técnica característica de este momento (García Borja 2015: 180, fig. 5.33; García Borja 2017: 110, fig. 433). Así, en el Tossal de les Bases (Alicante), en la fase Fase TBIII se ha citado un vaso completo de aspecto similar y borde reforzado, con impresiones seriadas bajo este (Tumba 5), siendo las cerámicas con decoración fina esgrafiada características de este momento (Rosser y Soler 2016: 240).

Fuera del ámbito peninsular, los bordes reforzados son frecuentes en el Chasense Antiguo del centro y

\footnotetext{
4 Vera Rodríguez, J. C. y Martínez Fernández, M. J. (en prensa): "El yacimiento neolítico del arroyo de Santa María (Almonte, Huelva)". En G. Martínez Fernández, J. Afonso Marrero, A. Dorado Alejos, C. Bashore Acero, F. Martínez Sevilla y J. A. Cámara Serrano (eds.): Actas del VI Congreso del Neolitico en la Península Ibérica. Granada, 22-24 de junio de 2016.
} 
sur de Francia (Van Willigen et al. 2010: 214; Gandelin y Vergély 2012: 92; Lepère 2012: 525), presentes en los niveles prechasenses de la Baume de Fontbregoua, junto a formas carenadas (Luzi y Courtin 2001: 480, fig. 8). Sería posible rastrear algunos de estos rasgos, incluyendo formas compuestas bitroncocónicas, en el Grupo de Michelsberg (Jeunesse et al. 2002-2003). Ahora bien no podemos sino especular con las hipotéticas relaciones existentes entre las tradiciones culturales de determinadas áreas de Europa continental y las contemporáneas del sur de Iberia, representadas por las cerámicas de la Fase I del Grañena Baja.

En cuanto a la talla, las láminas del yacimiento aportan nuevos datos para el debate sobre la evolución tecnológica en la Prehistoria reciente del sur peninsular. Se ha llegado a afirmar que el Neolítico Medio mantiene las características de la producción lítica del periodo anterior, definida por la elaboración de láminas/laminitas a presión y por el tratamiento térmico previo de los núcleos documentado desde los inicios del Neolítico (Martínez Fernández et al. 2010; Morgado y Pelegrin 2012: 223). En este sentido, los objetos tallados de Grañena I señalan la ruptura del método de preparación carenada/carenoide para la elaboración de láminas, pudiendo quedar relegado a un uso testimonial en el mejor de los casos.

Dicho cambio tecnológico implica un tiempo nuevo que perdurará hasta el IV milenio, cuya transformación dará lugar a la llamada Edad del Cobre. Esta se verá caracterizada desde su inicio por la tecnología de las láminas a presión con talón diedro agudo, coincidiendo con la aparición de las cazuelas carenadas (c. $3400 / 3300$ cal AC). Por tanto, los atributos técnicos del conjunto laminar de Grañena Baja permiten su distinción tanto de los propios del Neolítico Antiguo como de los de la Edad del Cobre. Las principales características tecnológicas de esta producción laminar se resumen en un talón liso espeso, productos de mediano y gran formato, y (aunque no exclusivamente) técnica de talla mediante percusión indirecta. Estas han sido observadas también en otros sitios arqueológicos del sur peninsular ubicados en la misma horquilla cronológica. Tal sería el caso de Palenque (Priego de Córdoba), niveles medios de Carigüela (Píñar) (Morgado et al. 2015: 42), La Loma (Aranda et al. 2012: 94), la fase IIIA y B de Cueva del Toro (Martin et al. 2004), Campo de Hockey (San Fernando) (Vijande et al. 2015) y el conjunto localizado bajo el túmulo de Casas de Don Pedro (Belmez, Córdoba), cuyas láminas presentan la característica sección trapezoidal regular, con la presencia de truncaduras retocadas y geométricos de ciertas dimensiones (Gavilán y Escacena 2009: fig. 14).

\subsection{Un foso segmentado para el Neolítico Medio andaluz}

La existencia de fosos de grandes dimensiones, con frecuencia dentro de esquemas planificados describiendo recintos circulares o subcirculares, es uno de los temas que más interés han suscitado en las últimas décadas en el estudio de la Prehistoria ibérica. Los testimonios más tempranos los encontramos en el Neolítico Antiguo como Mas d'Is, en el área de Alicante, alcanza hasta los $5 \mathrm{~m}$ de profundidad (Bernabeu et al. 2017: 344), y la Revilla del Campo, en Ambrona (Soria) (Rojo et al. 2006), ambas con sustanciales diferencias. En el Tossal de les Basses, diversas estructuras de escasa profundidad y trazado sinuoso se han puesto en relación con dispositivos de irrigación (Rosser y Soler 2016: 243).

En el sur de la península ibérica, al menos en lo que respecta al Valle del Guadalquivir, los fosos eran hasta ahora un fenómeno característico de la Edad del Cobre (Jiménez y Márquez 2016: 48). Como ya adelantamos, los primeros indicios de dichas construcciones se remontarían a la segunda mitad del IV milenio, destacando los ejemplos de Los Pozos (Higuera de Arjona, Jaén) (Hornos et al. 1990), aumentando progresivamente hasta alcanzar un gran número de ejemplos en los siglos centrales del III milenio cal AC (Bernabeu et al. 2017: 342; Aranda et al. 2016). Las hipótesis sobre su funcionalidad oscilan entre las de orden utilitario y las de cariz postprocesual, siempre según la óptica y los principios de quien aborde la problemática (Márquez y Jiménez 2012).

Los fosos segmentados (o con múltiples entradas) tienen escasa presencia en la península ibérica, desde al menos la segunda mitad del IV milenio (Bernabeu et al. 2017: 345; García García 2013; Valera 2013). Sin embargo, son comunes en Europa continental desde el horizonte $L B K$ (Jeunesse 2011: 33; Vaquer 2011: 233) con un amplio desarrollo a partir del Neolítico Medio (siglos centrales del V milenio) en gran parte del actual territorio francés (Soler et al. 2013: 635). Muchos de estos segmentos describen fosos de sección en $\mathrm{U}$ y fondo plano con anchura en superficie de 4-5 m (Peu à Charme, Charente) (Ard et al. 2016: 383). También es frecuente su asociación a trincheras paralelas que suelen ser interpretadas, al disponer de agujeros de poste, como zanjas para la inserción de una empalizada (Bréart 1984: 300; Jeunesse 2011: 11; Ard et al. 2016). Este rasgo no es contemplado, o no se conserva, en nuestro caso. Como el foso de Grañena Baja ha sido detectado tan sólo sobre una superficie de 1,9 ha excavadas en su totalidad, no podemos defender con seguridad su pertenencia a un recinto como tal. Sólo un estudio adecuado con técnicas de teledetección sobre el área aun conservada podría despejar 
dudas sobre la extensión real de este foso y su trazado. $\mathrm{Su}$ funcionalidad e interpretación sólo podrá ser evaluada una vez alcanzado dicho objetivo.

El resto de las estructuras correspondientes a esta fase, las proporcionalmente escasas de planta circular documentadas, se ven sujetas a las habituales interpretaciones formuladas sobre estructuras similares, relacionadas con su uso vinculado al almacenamiento, hábitat y transformación y procesamiento de materias primas. Por su parte las zanjas denominadas E-61, E-69 y E-171 muestran ciertas similitudes morfológicas entre sí en cuanto a trazado, presencia elementos pétreos de gran tamaño, evidencias de combustión y amortización con abundantes clastos. Sin embargo, dada su singularidad en el registro y a la escasez de materiales proporcionados, no resulta fácil proponer una interpretación funcional para las mismas.

\section{3. ¿Un Neolítico Medio "vacío"?}

La fase I de Grañena Baja supone un significativo aporte al conocimiento de las sociedades neolíticas del $\mathrm{V}$ milenio cal AC en las campiñas del Alto Guadalquivir, y por extensión, del sur de la península ibérica. Este fértil territorio, dominado por suelos margosos muy productivos para el cultivo del secano, cuenta con una riqueza arqueológica excepcional que ha propiciado el impulso en las últimas décadas de proyectos de investigación arqueológica, algunos de ellos basados en la prospección intensiva del territorio. La detección de numerosos enclaves arqueológicos fundamentalmente enmarcados en un contexto cronocultural de la segunda mitad del IV y III milenio, ha permitido alimentar diferentes interpretaciones sobre las dinámicas sociales y políticas a lo largo de la Prehistoria reciente en dicho territorio (Nocete 1994; Lizcano 1999; Zafra 2006; Nocete et al. 2010; Cámara y Riquelme 2015). En comparación, la escasa información relativa a las fases neolíticas previas ha sido argumentada en ocasiones atribuyendo escaso sedentarismo a estas poblaciones, así como a la existencia de un vacío ocupacional previo a una colonización agrícola propuesta para momentos avanzados del IV milenio cal AC (Nocete 1994: 277; Lizcano 1999: 26).

En tiempos recientes, diversos hallazgos han venido a cuestionar dicha premisa. Es el caso de los contextos neolíticos del Corte Inglés de Jaén (Serrano et al. 2011: 50, 333) o de las Sierras Subbéticas, beneficiadas por una red mejor conocida de ocupaciones al aire libre desde la segunda mitad del VI milenio cal AC (Gavilán y Vera 1997; Carrasco et al. 2011b; Martínez Sánchez y Vera 2017b). En esta región, la presencia de cerámicas pintadas y láminas de sílex de cierto tamaño y talón facetado o liso en la Loma (Íllo- ra, Granada) y Palenque (Priego de Córdoba) (Aranda et al. 2012: 95; Morgado et al. 2015: 38), vendría a cubrir el vacío en lo que respecta a finales del V y primera mitad del IV milenio cal AC. En este sentido, la excavación de Grañena Baja ha venido a arrojar nueva luz sobre un momento anterior, situado entre la denominada tradicionalmente "Cultura de las Cuevas con Cerámica Decorada del Neolítico" y la formación de las condiciones sociales y económicas que desembocaron en lo que hoy conocemos como Edad del Cobre.

El intervalo situado en la segunda mitad del V milenio, coincide con algunos hiatos y lagunas detectados en varias de las secuencias mejor estudiadas para la región mediterránea y del sur de la península ibérica (Bernabeu et al. 2008: 55). Así, el yacimiento granadino de la Peña de los Gitanos de Montefrío, ocupado desde el último tercio del VI milenio y con una larga prolongación a lo largo de toda la Edad del Cobre, presenta un hiato entre el 4800 y el $4200 \mathrm{cal}$ AC (Molina et al. 2017). Entre las formas cerámicas estudiadas a lo largo de su secuencia, no han podido reconocerse tipos afines a los identificados en la fase I de Grañena Baja (Gámiz 2018).

Ante la aparente evanescencia de los contextos correspondientes a la mayor parte del V milenio, parte de los investigadores implicados en el estudio del Neolítico Andaluz ha propuesto acabar con la idea de un Neolítico Medio. De este modo el proceso quedaría doblemente dividido entre un Neolítico Antiguo (o Inicial) y Reciente, una vez asimiladas dentro de una fase antigua las cerámicas propias del Neolítico de las Cuevas (Camalich y Martín 2013: 112; Martínez Sevilla 2016; Martín et al. 2017: 460). Otros investigadores, sin embargo, han asumido explícitamente una fase media en la revisión y estudio de algunas de las secuencias neolíticas más relevantes de Andalucía (Nerja) (García Borja et al. 2014: 112-113).

\section{CONCLUSIONES}

Como convención basada en cambios visibles a través del registro arqueológico, la división tripartita del Neolítico en Andalucía ha pasado por diferentes propuestas. Síntesis recientes han situado cronológicamente el Neolítico Medio en el V milenio cal AC, concretamente entre el 5000/4900 hasta la aparición de las primeras etapas del Neolítico reciente (Neolítico Reciente I o Neolítico tardío) hacia (4300/4200 cal AC). Este Neolítico Medio, como fase evolucionada, estaría definido más por la cultura material mueble que por los patrones de asentamiento o la economía. Ello contrasta con otros autores, que han llegado a afirmar que no se puede seguir sosteniendo la división tripar-

Trab. Prehist., 77, N. ${ }^{\circ}$ 1, enero-junio 2020, pp. 30-47, ISSN: 0082-5638

https://doi.org/10.3989/tp.2020.12245 
tita del Neolítico, ante la falta de separación entre el Antiguo y Medio.

En este debate, la Fase I de Grañena Baja constituye un hito de suma importancia para la caracterización de la cultura material y ocupación del territorio en las campiñas del Alto Guadalquivir y en el conjunto del sur de Iberia a mediados del V milenio. Sorprende en este sentido, su hallazgo en un territorio aparentemente bien conocido a nivel arqueológico, dibujando a todas luces una dinámica histórica mucho más compleja de lo que había sido esbozado hasta este momento. Ello obliga a replantear los esquemas asociados a las evoluciones sociales y al modo de ocupación del territorio entre el VI y el IV milenio cal AC en la Depresión del Guadalquivir.

Tanto la cerámica como la tecnología empleada en los instrumentos líticos suponen una ruptura evidente con tradiciones anteriores, constituyendo toda una novedad en el Neolítico del sur de la península ibérica. Resulta difícil de momento explicar las causas de dicha mutación, si bien podemos relacionarla con las diferentes tradiciones culturales del occidente mediterráneo y Europa continental durante el V milenio cal AC. A las afinidades con otros contextos peninsulares (como las esgrafiadas del País Valenciano, o las formas con sulco abaixo do bordo descritas en Portugal), se le suman los bordes reforzados al exterior propios del Chasense Antiguo y facies anteriores, donde se citan formas compuestas troncocónicas con carena media, comunes en el Mediodía francés y al norte de los Alpes.

De confirmarse, el hallazgo de un foso segmentado del $\mathrm{V}$ milenio constituye toda una novedad en el panorama arqueológico del sur de la península ibérica. De nuevo, quizá haya que buscar las afinidades más próximas en Europa continental, donde hay constancia de dichas estructuras desde mediados del VI milenio, viendo un enorme desarrollo a mediados del milenio siguiente. Ello, sin duda ilumina un período casi desconocido en la Prehistoria Reciente andaluza, a la par que apunta a un mundo "menos peninsular" y más interconectado a la dinámica social del continente europeo.

\section{BIBLIOGRAFÍA}

Afonso Marrero, J. A. 1993: Aspectos técnicos de la producción lítica de la prehistoria reciente de la alta Andalucía y el sureste. Tesis Doctoral. Departamento de Prehistoria y Arqueología. Universidad de Granada, Granada. http://hdl.handle.net/10481/14511

Aranda Jiménez, G.; Camalich Massieu, M. D.; Martín Socas, D.; Morgado Rodríguez, A.; Martínez Sevilla, F.; Lozano Rodríguez, J. A.... y Román Punzón, J. 2012: La Loma (Íllora, Granada). Un yacimiento de fosas del VI-IV milenios Cal BC. Arqueología. Monografías [recurso electrónico], Junta de Andalucía. Sevilla.

Aranda Jiménez, G.; Lozano Medina, Á.; Escudero Carrillo, J.; Sánchez Romero, M.; Alarcón García, E.; Fernández Martín, S.... y Barba
Colmenero, V. 2016: "Cronología y temporalidad de los recintos de fosos prehistóricos: el caso de Marroquíes Bajos (Jaén)". Trabajos de Prehistoria 73 (2): 231-250. https://doi.org/10.3989/tp.2016.12171

Ard, V.; Aoustin, D.; Mathé, V.; Onfray, M.; Legrand, V. y Bouchet, É. 2016: "Découverte d'un habitat ceinturé du début du Néolithique moyen dans le Centre-Ouest de la France: le Peu à Charmé (Charente)". Bulletin de la Société préhistorique française 113: 382-385.

Arribas Palau, A. y Molina González, F. 1979: El poblado de 'los Castillejos' en las Peñas de los Gitanos (Montefrio, Granada). Campaña de excavaciones de 1971. El corte núm. 1. Cuadernos de prehistoria de la Universidad de Granada, Serie monográfica 3. Granada.

Arteaga Matute, O.; Ramos Muñoz, J. y Roos, A. M. 1998: "La Peña de la Grieta (Porcuna, Jaén). Una nueva visión de los cazadoresrecolectores del mediodía atlántico-mediterráneo desde la perspectiva de sus modos de vida y trabajo en la Cuenca del Guadalquivir". En Las culturas del Pleistoceno Superior en Andalucia, I ${ }^{e r}$ Simposio de Prehistoria Cueva de Nerja (Nerja 1996): 75-109. Málaga.

Balsera Nieto, V.; Bernabeu Aubán, J.; Costa-Caramé, M.; Díaz-del-Río, P.; García Sanjuán, L. y Pardo Gordó, S. 2015: "The radiocarbon chronology of Southern Spain's Late Prehistory (5600-1000 Cal BC): a comparative review". Oxford Journal of Archaeology 34: 156-215. https://doi.org/10.1111/ojoa.12053

Bernabeu Aubán, J.; Molina Balaguer, L.; Orozco Köhler, T.; Díez Castillo, A. y Barton, M. C. 2008: "Los valles del Serpis (Alicante): 20 años de trabajo de campo". En M. S. Hernández Pérez, J. A. Soler Díaz y J. A. López Padilla (eds.): Actas del IV Congreso del Neolitico Peninsular (Alicante, 2006): 50-57. Alicante.

Bernabeu Aubán, J.; Orozco Köhler, T.; Díaz del Río Español, P.; Pardo Gordó, S.; Balsera Nieto, V. y Consuegra Rodríguez, S. 2017: "Prehistoric ditches and ditched enclosures in Iberia: A survey based on recent findings". En H. Meller y S. Friederich (eds.): SalzmündeRegel oder Ausnahme? Internationale Tagung vom 18. bis 20. Oktober 2012 in Halle (Saale). Tagungen des Landesmuseums für Vorgeschichte Halle 16. Halle: 341-351.

Binder, D.; Collina, C.; Guilbert, R.; Perrin, T. y García-Puchol, O. 2012: "Pressure-knapping blade production in the North-Western Mediterranean Region during the seventh millennium cal B.C". En P. M. Desrosiers (ed.): The emergence of pressure blade making. Springer. Nueva York: 199-217.

Bréart, B. 1984: "Le site néolithique du 'Champ de Bataille' à l'Étoile (Somme): une enceinte à fossé interrompu'. Revue archéologique de Picardie 1-2: 293-310. https://doi.org/10.3406/pica.1984.1423

Camalich Massieu, M. D. y Martín Socas, D. 2013: "Los inicios del Neolítico en Andalucía. Entre la tradición y la innovación". Menga 4: 103-129.

Cámara Serrano, J. A. y Riquelme Cantal, J. A. 2015: "Formas y condiciones de la sedentarización en el Alto Guadalquivir. Economía y hábitat entre el IV y el III milenios a.C.” En V. S. Gonçalves y A. C. Sousa (eds.): Actas do $5^{\circ}$ Congresso do Neolitico Peninsular (Lisboa 2011): 339-348. Lisboa.

Cámara Serrano, J. A.; Riquelme Cantal, J. A.; Pérez Bareas, C.; Lizcano Prestel, R.; Burgos Juárez, A. y Torres Torres, A. 2010: "Sacrificio de animales y ritual en el Polideportivo de Martos-La Alberquilla (Martos, Jaén)". Cuadernos de Prehistoria de la Universidad de Granada 20: 297-327.

Carrasco Rus, J.; Navarrete Enciso, S.; Capel Martínez, J. y Gámiz Jiménez, J. 1987: "Las 'Catorce Fanegas', un yacimiento neolítico al aire libre en la Vega de Granada". Revista del Centro de Estudios Históricos de Granada y su Reino 1: 9-36.

Carrasco Rus, J.; Pachón Romero, J. A.; Gámiz Jiménez, J. y Martínez Sevilla, F. 2011a: "El poblamiento neolítico en el Subbético Interno del Poniente de Granada". Antiquitas 23: 5-45.

Carrasco Rus, J.; Pachón Romero, J. A. y Martínez Sevilla, F. 2011b: "Las necrópolis en cuevas del Neolítico antiguo y medio en las áreas montañosas de la costa de Granada". En J. Abellán, M. Lazarich González y V. Castañeda Fernández (eds.): Homenaje al profesor Antonio Bellido: 81-103. Cádiz.

Fernández García, I. 2013: "Yacimiento neolítico en la cueva del Perro (Periana, Málaga). Estudio de materiales". Baetica. Estudios de Arte, Geografia e Historia 35: 99-135. 
Gámiz Caro, J. 2018: La cerámica neolítica de Los Castillejos (Montefrío, Granada). Estudio tipológico, decorativo y tecnológico. Dpto. de Prehistoria y Arqueología, Universidad de Granada. Granada. http://hdl.handle.net/10481/51578

Gandelin, M. y Vergély, H. 2012: "Les productions céramiques du Chasséen méridional entre l'Hérault et l'Orb: nouvelles séquences typochronologiques". Archéopages. Archéologie et société 3: 88-95. https://doi.org/10.4000/archeopages.475

García Borja, P. 2015: El estilo de la cerámica neolítica de la Cova de la Sarsa (Bocairent, València). Dept. de Prehistòria i Arqueologia. Universitat de València. Valencia. tesis http://hdl.handle.net/10550/50553

García Borja, P. 2017: Las cerámicas neolíticas de la Cova de la Sarsa (Bocairent, Valencia). Tipología, estilo e identidad. Serie de Trabajos Varios 120. Servicio de Investigación Prehistórica del Museo de Prehistoria de Valencia. Valencia.

García Borja, P.; Aura Tortosa, J. E.; Jordá Pardo, J. F. y Salazar-García, D. C. 2014: "La cerámica neolítica de la Cueva de Nerja (Málaga, España): salas del Vestíbulo y la Mina”. Archivo de Prehistoria Levantina XXX: $81-131$

García Borja, P. y Pérez Jordà, G. 2012: "Ensayo tipológico para el estudio de cerámica prehistórica del País Valenciá. Aplicación a colecciones del Bronce Final". Lucentum XXXI: 31-59. https://doi.org/10.14198/lvcentvm2012.31.03

García García, M. 2013: "Las Pozas (Casaseca de las Chanas, Zamora): dos nuevos recintos de fosos calcolíticos en el Valle del Duero". Trabajos de Prehistoria 70 (1): 175-184. https://doi.org/10.3989/tp.2013.12108

Gavilán Ceballos, B. y Escacena Carrasco, J. L. 2009: “Acerca del Primer Neolítico de Andalucía Occidental. Los tramos medio y bajo de la Cuenca del Guadalquivir". Mainake XXXI: 311-351.

Gavilán Ceballos, B. y Vera Rodríguez, J. C. 1997: "Nuevos datos sobre los patrones de poblamiento Neolítico y Calcolítico el aire libre en el piedemonte de las Sierras Subbéticas". Antiqvitas 8: 23-42.

Gavilán Ceballos, B. y Vera Rodríguez, J. C. 2001: "El Neolítico en la Alta Andalucía: cuestiones sobre la caracterización de sus fases". Spal 10: 177-183. https://doi.org/10.12795/spal.2001.i10.11

Hornos Mata, F.; Nocete Calvo, F. y Pérez Bareas, C. 1990: "Actuación arqueológica de urgencia en el yacimiento de los Pozos en Higuera de Arjona (Jaén)". Anuario Arqueológico de Andalucia 1988: 198-202.

Jeunesse, C. 2011: "Enceintes à fossé discontinu et enceintes à pseudofossé dans le Néolithique d'Europe centrale et occidentale". En A. Denaire, C. Jeunesse y P. Lefranc (eds.): Nécropoles et enceintes danubiennes du Ve millénaire dans le Sud-Ouest de l'Allemagne. Presses universitaires de Strasbourg. Strasbourg: 31-72.

Jeunesse, C.; Lefranc, P. y Denaire, A. 2002-2003: "Groupe de Bischheim, origine du Michelsberg, genèse du groupe d'Entzheim. La transition entre le Néolithique moyen et le Néolithique récent dans les régions rhénanes". Cahiers de l'Association pour la Promotion de la Recherche Archéologique en Alsace 18-19: 1-280.

Jiménez Jáimez, V. y Márquez Romero, J. E. 2016: "Prehistoric ditched enclosures and necropolises in Southern Iberia: a diachronic overview". En V. Ard y L. Pillot (eds.): Giants in the landscape: Monumentality and territories in the European Neolithic. Proceedings of the XVII UISPP World. Congress (Burgos, Spain 2014). Archaeopress Archaeology. Oxford: 57-68.

Lepère, C. 2012: "Chronologie des productions céramiques et dynamiques culturelles du Chasséen de Provence". Bulletin de la Société préhistorique française 109: 513-545. https://doi.org/10.3406/bspf.2012.14173

Liesau von Lettow-Vorbeck, C. y Morales Muñiz, A. 2012: "Las transformaciones económicas del Neolítico en la Península Ibérica: la ganadería”. En M. Rojo, R. Garrido e I. García (eds.): El Neolítico en la Península Ibérica y su contexto europeo. Cátedra. Madrid: 107-128.

Lizcano Prestel, R. 1999: El Polideportivo de Martos (Jaen): un yacimiento neolitico del IV milenio a.C. Obra social y Cultural Cajasur. Córdoba.

Lizcano Prestel, R.; Cámara Serrano, J. A.; Contreras Cortés, F.; Pérez Bareas, C. y Burgos Juárez, A. 2004: "Continuidad y cambio en comunidades calcolíticas del Alto Guadalquivir”. En Actas del II y
III Simposio de Prehistoria Cueva de Nerja. Fundación Cueva de Nerja. Málaga: 159-175.

Lizcano Prestel, R.; Cámara Serrano, J. A.; Riquelme Cantal, J. A.; Cañabate, M. L.; Sánchez, A. y Afonso Marrero, J. A. 1992: “El Polideportivo de Martos. Producción económica y símbolos de cohesión en un asentamiento del Neolítico Final en las campiñas del Alto Guadalquivir". Cuadernos de Prehistoria de la Universidad de Granada 16-17: 5-101.

Luzi, C. y Courtin, J. 2001: "La céramique des niveaux préchasséens de la Baume Fontbrégoua (Salernes, Var)". Bulletin de la Société préhistorique française 98: 471-484. https://doi.org/10.3406/bspf.2001.12533

Márquez Romero, J. E. y Jiménez Jaimez, V. 2012: "Interpretando los recintos de fosos de la Prehistoria Meridional Europea: la tesis belicista a examen". En J. M. Jiménez Arenas y F. A. Muñoz Muñoz (eds.): La paz, partera de la Historia. Universidad de Granada. Granada: $69-86$.

Martín Socas, D.; Cámalich Massieu, M. D.; Caro Herrero, J. L. y Rodríguez-Santos, F. J. 2017: "The beginning of the Neolithic in Andalusia”. Quaternary International 470B: 451-471. https://doi.org/10.1016/j.quaint.2017.06.057

Martín Socas, D.; Cámalich Massieu, M. D. y González Quintero, P. 2004: La Cueva del Toro (Sierra de El Torcal-Antequera-Málaga). Un modelo de ocupación ganadera en el territorio andaluz entre el VI y II milenios ANE. Consejería de Cultura, Junta de Andalucía. Sevilla.

Martínez Fernández, G.; Afonso Marrero, J. A.; Cámara Serrano, J. A. y Molina González, F. 2010: “Contextualización cronológica y análisis tecno-tipológico de los artefactos tallados del Neolítico antiguo de los Castillejos (Montefrío, Granada)". En F. J. Gibaja Bao y A. F. Carvalho (eds.): Os últimos caçadores- recolectores e as primeiras comunidades produtoras do sul da Península Ibérica e do Norte de Marrocos (Actas do Workshop Faro 2009). Promontoria Monográfica 15, Universidade do Algarve. Faro: 163-172.

Martínez Sánchez, R. M. 2017: "Los restos faunísticos del Neolítico del Castillo de Doña Mencía; ¿preferencias ganaderas o especialización pastoril en el Subbético y Campiña Alta de la Andalucía Central?" En R. M. Martínez Sánchez y J. C. Vera Rodríguez (eds.): El enclave neolítico al aire libre del Castillo de Doña Mencía (Córdoba). Una mirada a los primeros agricultores y ganaderos de las campiñas del Guadalquivir Medio. Onoba Monografías 1, Universidad de Huelva. Huelva: 99-109.

Martínez Sánchez, R. M. y Vera Rodríguez, J. C. 2017a: “Aproximación a los instrumentos líticos”. En R. M. Martínez Sánchez y J. C. Vera Rodríguez (eds.): El enclave neolitico al aire libre del Castillo de Doña Mencía (Córdoba). Una mirada a los primeros agricultores y ganaderos de las campiñas del Guadalquivir Medio. Onoba Monografías 1, Universidad de Huelva. Huelva: 53-74.

Martínez Sánchez, R. M. y Vera Rodríguez, J. C. 2017b: El enclave neolitico al aire libre del Castillo de Doña Mencía. Una mirada a los primeros agricultores y ganaderos de las campiñas del Guadalquivir Medio. Onoba Monografías 1, Universidad de Huelva. Huelva.

Martínez Sevilla, F. 2016: Un adorno reflejo de una sociedad. Los brazaletes líticos del neolítico de Iberia (VI-V milenio a.C.). Tecnología, funcionalidad y circulación. Universidad de Granada. Granada. http:// hdl.handle.net/10481/48573

Molina González, F.; Cámara Serrano, J. A. y López Sáez, J. A. 2012: "Andalucía". En M. A. Rojo Guerra, R. Garrido Pena e I. García Martínez de Lagrán (eds.): El Neolítico en la Península Ibérica y su contexto europeo. Cátedra. Madrid: 405-462.

Molina González, F.; Cámara Serrano, J. A.; Afonso Marrero, J. A.; Gámiz Caro, J.; Capel Martínez, J. y Martínez Fernández, G. 2017: "Hiatus in an archaeological multilevel site: Los Castillejos in Las Peñas de los Gitanos (Montefrío, Granada)". En M. Cupitò, M. Vidale y A. Angelini (eds.): Beyond limits. Studi in onore di Giovanni Leonardi. Padova University Press. Padova: 91-100.

Morgado Rodríguez, A. y Lozano Rodríguez, J. A. 2014: "Objetos de sílex, marcadores litológicos de la circulación. Geoarqueología de la producción laminar especializada del sur de Iberia (c. VI-V mil. cal. BP)”. En E. García Alfonso y B. Ruiz González (eds.): Movilidad,

Trab. Prehist., 77, N. ${ }^{\circ}$ 1, enero-junio 2020, pp. 30-47, ISSN: 0082-5638

https://doi.org/10.3989/tp.2020.12245 
contacto y cambio. Actas del II Congreso de Prehistoria de Andalucía. Junta de Andalucía. Sevilla: 121-137.

Morgado Rodríguez, A.; Lozano Rodríguez, J. A. y Pelegrin, J. 2011: "Las explotaciones prehistóricas del sílex de la formación Milanos (Granada, España)". Menga 2: 235-269.

Morgado Rodríguez, A.; Martínez Sánchez, R. M. y Carmona Ávila, R. 2015: "Puntualizaciones sobre el tránsito V-IV milenio cal. AC en la Alta Andalucía. El primer asentamiento en el casco urbano de Priego de Córdoba". Antiqvitas 27: 31-47.

Morgado Rodríguez, A. y Pelegrin, J. 2012: "Origin and development of pressure blade production in the Southern Iberian peninsula $\left(6^{\text {th }}-3^{\text {rd }}\right.$ Millennia BC)". En P. M. Desrosiers (ed.): The emergence of pressure blade making. Springer. Nueva York: 219-235.

Navarrete Enciso, S. 1976: La Cultura de las Cuevas con cerámica decorada en Andalucía Oriental. Caja de Ahorros de Granada-Universidad de Granada. Granada.

Navarrete Enciso, S.; Capel Martínez, J.; Linares, J.; Huertas, F. y Reyes, E. 1991: Cerámicas neolíticas de la provincia de Granada: materias primas y técnicas de manufacturación. Universidad de Granada. Granada.

Neves, C. 2015: “A 2. metade do V Milénio no Ocidente Peninsular: algumas problemáticas a partir da cultura material”. En V. S. Gonçalves y A. C. Sousa (eds.): Actas do $5^{\circ}$ Congresso do Neolítico Peninsular (Lisboa 2011): 314-321. Lisboa.

Nocete Calvo, F. 1994: La formación del Estado en las campiñas del Alto Guadalquivir (3000-1500 a.n.e.). Monográfica Arte y Arqueología, Universidad de Granada. Granada.

Nocete Calvo, F. 2001: Tercer milenio antes de nuestra era: relaciones y contradicciones centro/periferia en el valle del Guadalquivir. Bellaterra. Barcelona.

Nocete Calvo, F.; Lizcano Prestel, R.; Peramo, A. y Gómez del Toro, E. 2010: "Emergence, collapse and continuity of the first political system in the Guadalquivir Basin from the fourth to the second millennium BC: The long-term sequence of Úbeda (Spain)". Journal of Anthropological Archaeology 29: 219-237. https://doi.org/10.1016/j.jaa.2010.03.001

Pelegrin, J. 2006: "Long blade technology in the old world: an experimental approach and some archaeological results". En J. Apel y K. Knutsson (eds.): Skilled production and social reproduction. Aspects on traditional stone-tool technology. Uppsala University Press. Uppsala: $37-68$.

Pelegrin, J. 2012: "New experimental observations for the characterization of pressure blade production techniques". En P. M. Desrosiers: The emergence of pressure blade making. From origin to modern experimentation. Springer. New York: 465-500.

Pellicer Catalán, M. 1995: "Las culturas del Neolítico-Calcolítico en Andalucía Oriental”. Espacio, Tiempo y Forma. Serie I, Nueva Época. Prehistoria y Arqueología 8: 81-134.

Pellicer Catalán, M. y Acosta Martínez, P. 1990: La Cueva de la Dehesilla (Jerez de la Frontera): las primeras civilizaciones productoras en Andalucía Occidental. Centro de Estudios Históricos Jerezanos. Jerez de la Frontera.

Pellicer Catalán, M. y Acosta Martínez, P. 1997: El Neolítico y Calcolítico de la Cueva de Nerja en el contexto andaluz. Patronato de la Cueva de Nerja. Málaga.

Pérez Bareas, C. 2010: "Prehistoria, Antigüedad y Etapa Visigoda". En M. F. Moral Jimeno (ed.): Baeza: Arte, Patrimonio. Ayuntamiento de Baeza. Jaén: 131-149.

Pérez Bareas, C.; Afonso Marrero, J. A.; Cámara Serrano, J. A.; Contreras Cortés, F. y Lizcano Prestel, R. 1999: "Clasificación cultural, periodización y problemas de compartimentación en el Neolítico de la Alta Andalucía”. En J. Bernabeu Aubán y T. Orozco Köhler (eds.): Actas del II congrés del Neolític a la Península Ibèrica. Saguntum: Papeles del Laboratorio de Arqueología de Valencia, Extra 2. Valencia: 485-492.

Reimer, P. J.; Bard, E.; Bayliss, A.; Beck, J. W.; Black, P. G.; Bronk Ramsey, C... y Van der Plicht, J. 2013: "IntCal13 and Marine13 Radiocarbon Age Calibration Curves 0-50,000 Years cal BP”. $R a$ diocarbon 55: 1869-1887. https://doi.org/10.2458/azu js rc.55.16947

Rojo Guerra, M. A.; Kunst, M.; Garrido Pena, R. y García Martínez de Lagrán, I. 2006: "La neolitización de la Meseta Norte a la luz del C-14: análisis de 47 dataciones absolutas inéditas de dos yacimientos domésticos del Valle de Ambrona, Soria, España". Archivo de Prehistoria Levantina XXVI: 39-100.

Rosser Limiñana, P. y Soler Ortiz, S. 2016: "Propuesta de fases cronológicas para el asentamiento neolítico del Tossal de les Bases (Alicante, España)". En H. Bonet Rosado (ed.): Del neolitic a l'Edat del Bronze en el Mediterrani Occidental. Estudis en homenatge a Bernat Martí Oliver. Museu de Prehistòria de València. Valencia: 225-248.

Sáez Pérez, L. y Martínez Fernández, G. 1981: "El yacimiento neolítico al aire libre de la Molaina (Pinos Puente, Granada)". Cuadernos de Prehistoria de la Universidad de Granada 6: 17-34.

Serrano Peña, J. L.; Portero Fernández, V. y Cano Carrillo, J. 2011: Historia de un arroyo: de Marroquies Bajos al centro comercial El Corte Inglés de Jaén. El Corte Inglés. Jaén.

Soler, L.; Save, S.; Dupont, C. y Roque, C. 2013: "Le Fief des Quatre Chevaliers. Étude paléo-environnementale aux abords d'une enceinte néolithique sur le littoral atlantique à Périgny (Charente-Maritime, France)". En M. Y. Daire, C. Dupont, A. Baudry, C. Billiard, J. M. Large, L. Lespez, E. Normand y Ch. Scarre (eds.): Anciens peuplements littoraux et relations Homme/Milieu sur les cotes de l'Europe atlantique. British Archaeological Reports International Series 2570, Oxford: 635-646.

Valera, A. C. 2013: "Cronologia dos recintos de fossos da Pré-História Recente em território português". En J. Morais Arnaud, A. Martins y C. Neves (eds.): Arqueologia em Portugal. 150 anos (I Congresso da Associação dos Arqueólogos Portugueses (Lisboa 2013): 335-343. Lisboa.

Van Willigen, S.; D’Anna, A.; Renault, S. y Sargiano, J.-P. 2010: "Le Néolithique moyen du sud-est de la France - 50 ans de recherches". En X. Delestre y H. Marchesi (eds.): Archéologie des rivages méditerranéens: 50 ans de recherche. Errance. Paris: 211-221.

Vaquer, J. 2011: "Les enceintes à fossés du Néolithique, du Chalcolithique et du Bronze ancien dans la zone nord pyrénéenne". Revista d'Arqueologia de Ponent 11: 233-252.

Vera Rodríguez, J. C. 1997: "Industrias talladas de los asentamientos calcolíticos de Sierra Palacios (Belmez, Córdoba): una secuencia tecnológica del IV al III milenios a.C.”. En R. Balbín Behrmann y P. Bueno Ramírez (eds.): Actas del II Congreso de Arqueología Peninsular (Zamora 1996): 185-198. Zamora.

Vijande Vila, E.; Dominguez-Bella, S.; Cantillo Duarte, J.; Martínez López, J. y Barrena Tocino, A. 2015: "Social inequalities in the Neolithic of southern Europe: The grave goods of the Campo de Hockey necropolis (San Fernando, Cádiz, Spain)". Comptes Rendus de Palevol 14: 147-162. https://doi.org/10.1016/j.crpv.2014.11.004

Zafra de la Torre, N. 2006: De los campamentos nómadas a las aldeas campesinas. La provincia de Jaén en la Prehistoria. Universidad de Jaén. Jaén.

Zafra, N. y Pérez Bareas, C. 1993: "Excavación arqueológica de emergencia en el yacimiento del Cerro de Los Horneros. Pedanía de Las Escuelas. Baeza, 1991". Anuario Arqueológico de Andalucía 1991, III: $258-264$ 